\title{
Pten Haplodeficiency Accelerates Liver Tumor Growth in miR-122a-Null Mice via Expansion of Periportal Hepatocyte-Like Cells
}

\author{
Wei-Ling Tu, ${ }^{*}$ Li-Ru You, ${ }^{\dagger \ddagger}$ Ann-Ping Tsou, ${ }^{\S}$ and Chun-Ming Chen ${ }^{* \ddagger}$
}

From the Department of Life Sciences and Institute of Genome Sciences, ${ }^{*}$ the Institute of Biochemistry and Molecular Biology, ${ }^{\dagger}$ the Cancer Progression Research Center ${ }^{\ddagger}$ and the Department of Biotechnology and Laboratory Science in Medicine, ${ }^{\S}$ National Yang-Ming University, Taipei, Taiwan

Accepted for publication July 26, 2018.

Address correspondence to Chun-Ming Chen, Ph.D., Department of Life Sciences and Institute of Genome Sciences, National Yang-Ming University, No. 155, Li-Nong St, Section 2, Taipei 112, Taiwan. E-mail: cmchen@ym. edu.tw.

\begin{abstract}
This study aimed to shed light on the molecular and cellular mechanisms responsible for initiation and progression of liver malignancies by examining the role of phosphatase and tensin homolog on chromosome 10 (Pten) in liver tumor progression in miR-122a (Mir122a)-null mice. We generated and monitored liver tumor initiation in Mir122a-null Pten heterozygous (Mir122a $a^{-/} ;$Pten $^{+/-}$and Mir122a $a^{-/-} ;$Alb-Cre;Pten ${ }^{f x /+}$ ) mice and compared the results with those in Mir122a $a^{-/-}$mice. Both Mir122a $a^{-/-} ;$Pten $^{+/-}$and Mir122a $a^{-/-} ;$Alb-Cre;Pten ${ }^{f x /+}$ mice developed visible liver tumor nodules at 6 months of age. In premalignant livers of Mir122a $a^{-/-} ;$Pten $^{+/-}$mice, decreased PTEN and increased phosphorylated AKT were specifically observed in periportal cells, associated with inflammatory and fibrotic microenvironments. Furthermore, IL-1 $\beta$ and tumor necrosis factor- $\alpha$ levels significantly increased in Mir122a $a^{-/-} ;$Pten $^{+/-}$premalignant livers at 6 months of age. Oval cells expressing A6, epithelial cell adhesion molecule, keratin (K) 8, K19, and SRY (sex determining region Y)-box 9 (SOX9) were present in both Mir122a $a^{-/-}$and Mir122a $a^{-/-} ;$Pten $^{+/-}$livers. Interestingly, a hybrid hepatocyte-like population with intermediate levels of K8, HNF $4 \alpha$, and SOX9 was located proximally to the oval cells in Mir122a $a^{-/-} ;$Pten $^{+/-}$livers. Lineage-tracing experiments revealed that these intermediate levels of K8 hepatocyte-like cells may be the cells of origin for Mir122a $a^{-/-} ;$Pten ${ }^{+/-}$liver tumors. These findings suggest that inflammatory microenvironments in the periportal area of Mir122a-null mice may locally cause Pten down-regulation and expand tumor-initiating cells, causing hepatocellular carcinoma. (Am J Pathol 2018, 188: 2688-2702; https://doi.org/10.1016/ j.ajpath.2018.07.019)
\end{abstract}

Liver malignancies can be driven by a variety of factors, including extrinsic (eg, viral infection, diet, and toxic chemicals) and intrinsic (genetic and epigenetic changes) insults. ${ }^{1,2}$ Most liver malignancies are hepatocellular carcinoma (HCC) and cholangiocarcinomas that result in high morbidity and mortality rates in underdeveloped and developing countries and have elevated incidences in developed countries. ${ }^{3,4}$ Although multiple factors involved in hepatic tumorigenesis have been intensively studied, the molecular and cellular mechanisms responsible for initiation and progression of liver malignancies remain elusive to date.

miR-122 (official name MIR122) is the major miRNA of the liver. ${ }^{5}$ Expression of miR-122a in the mouse liver begins around mouse embryonic day 12.5 and reaches maximal levels at birth and thereafter. ${ }^{6,7}$ Functionally, miR-122 regulates cholesterol and fatty acid metabolism. ${ }^{8,9}$ Expression of miR-122 is reduced in cases of $\mathrm{HCC}^{10-13}$ and is linked to poor prognosis and metastasis potential among patients with HCC. ${ }^{12,14,15}$ Recently, miR-122a-null mice have been shown to exhibit

Supported by the National Health Research Institutes grants NHRIEX106-10515BI and NHRI-EX107-10515BI (C.-M.C.); the Ministry of Education Aim for the Top University Plan and the Featured Areas Research Center Program within the framework of the Higher Education Sprout Project; and the Ministry of Science and Technology grants MOST 104-2320-B-010-025, MOST 105-2320-B-010-003, and MOST 105-2320B-010-028-MY3 (C-M.C.).

Disclosures: None declared. 
early-onset (at 2 months of age) liver inflammation, steatosis, and fibrosis and to subsequently develop HCC over 1 year. ${ }^{16,17}$

The phosphatase and tensin homolog on chromosome 10 $(P T E N)$ is a dual functional phosphatase and is a tumor-suppressor gene involved in a variety of malignancies. ${ }^{18-21}$ Decreased levels of PTEN in clinical HCC specimens have been reported. ${ }^{22-26}$ However, PTEN mutation appears to be a rare event in HCC. ${ }^{27-30}$ Hepatocyte-specific Pten ablation in mice results in the development of steatohepatitis, metabolic disorders, hepatomegaly at 6 months, hepatic adenomas at 10 to 11 months, and HCC at 18 to 19 months. ${ }^{31,32}$ Also, $\mathrm{CD} 133^{+} \mathrm{CD} 45^{-}$cells with stem/progenitor properties are increased at the premalignant stage and act as diseaseinitiating cells that cause liver cancer in the hepatocytespecific Pten-ablated mice. ${ }^{33}$ Thus, PTEN down-regulation may play a crucial role to drive or expand the diseaseinitiating cell populations to promote liver malignancies. Interestingly, decreased PTEN levels are observed in the Mir122a-null hepatic tumors that developed at 14 months of age. ${ }^{16}$ However, it remains unclear how PTEN downregulation drives Mir122a-deficient hepatic tumorigenesis. Furthermore, the cellular origin for precancer or cancer lesions of Mirl22a-null mice is largely undefined.

The cells of origin for liver malignancies are currently debatable. Previously, the ductular reactive cells in various human liver diseases and their equivalent oval cells in rodent liver injury models were postulated to have a progenitor property and were implicated as the cells of origin for HCC. ${ }^{34-37}$ However, the activated oval cells traced by the lineage-tracing approaches, which are conducted in diverse genetically and chemically induced HCC mouse models, do not cause HCC. ${ }^{38-40}$ A newly identified periportal hepatocyte subtype expressing a low level of SRY (sex determining region Y)-box 9 (SOX9), called hybrid hepatocytes, has greater regenerative potential than the oval cells. However, both hybrid hepatocytes and oval cells cannot cause diethylnitrosamine (DEN)-induced and chronic steatohepatitis-induced hepatic nodules and HCC. ${ }^{39}$ Interestingly, in a mouse HCC model induced by hepatocyte-specific expression of human unconventional prefoldin RNA polymerase II subunit 5 interactor, ${ }^{41}$ the $\mathrm{HCC}$ can be generated from hepatocytes and expanded SOX9-expressing hepatic progenitor cells. ${ }^{42}$ Therefore, these lineage-tracing experiments in newly examined HCC mouse models suggest that HCC is predominantly developed from hepatocytes, but also possibly developed from oval progenitor cells in a context-dependent manner.

In this study, we monitored Pten haplodeficiency in Mir122a-null liver tumor progression. We identified downregulation of Pten in the periportal parenchyma and found aberrantly expanded keratin 8 (K8)/SOX9/hepatocyte nuclear factor $4 \alpha(\mathrm{HNF} 4 \alpha)$ hepatocyte-like cells that may be the cells of origin causing liver cancer.

\section{Materials and Methods}

\section{Mice}

The Mir $122 a^{-/-}$mice on a C57BL/6J;129 mixed background were described previously. ${ }^{16}$ To generate $\mathrm{Pten}^{+/-}$mice, Pten $^{f x / f x}$ mice $^{43}$ from The Jackson Laboratory (Bar Harbor, ME) were bred with Prm-Cre transgenic mice. ${ }^{44}$ The Pten $^{+/-}$ mice carrying the exon 5-deleted allele of Pten were obtained from the progeny of Prm-Cre;Pten ${ }^{f x / t}$ mice. The Pten ${ }^{+/-}$ mice were further crossed with $\mathrm{C} 57 \mathrm{BL} / 6 \mathrm{~J}$ wild-type mice for 10 generations and then maintained on a C57BL/6 J congenic background. Mirl22a $a^{-/} ;$Pten $^{+/-}$mice were obtained by intercrossing Mirl22a $a^{-/-}$and Mirl22a ${ }^{+/-} ;$Pten $^{+/-}$mice. Albumin $(A l b)-C r e$ mice $^{45}$ were obtained from The Jackson Laboratory and used to tissue specifically delete monoallelic Pten in Mirl22a $a^{-1-} ;$ Alb-Cre;Pten ${ }^{f x /+}$ mice. The K18$E G F P ; K 8-C r e E R^{T 2}$ transgenic mice ${ }^{46,47}$ and Cre reporter $R 26 R^{\text {lacZ/+ }}$ mice ${ }^{48}$ were used for lineage-tracing experiments. All animals were housed in the specific pathogen-free areas on a 12:12-hour dark/light cycle in the Laboratory Animal Center of National Yang-Ming University. All animal studies were performed with the approval of the Institutional Animal Care and Use Committee at National Yang-Ming University.

\section{Genotyping of Mice}

Genomic DNA from 10-day-old mouse tails was isolated and subjected to PCR genotyping. Mir122a alleles were detected by the primers WT-1 (forward, 5'-GTGTTGGCCAGCTTATTCCAAAGG-3'), Rev-2 (reverse, $5^{\prime}$-CTCACTGTAAAGGTCACAGGTGC- $3^{\prime}$ ), and KO-1 (forward, 5'-CAACAATCCTGTCAGCACCATAG-3'), yielding a 429-bp wild-type allele and an 825-bp null allele. The Pten alleles were detected by the primers oIMR1952 (forward, 5'-ACTCAAGGCAGGGATGAGC-3'), exon 5B (reverse, 5'-AATCTAGGGCCTCTTGTGCC- ${ }^{\prime}$ ), and pBS1 (reverse, $5^{\prime}$-GCTTGATATCGAATTCCTGCAGC-3'), yielding a 1000-bp wild-type allele, a 1100bp Pten $^{f x}$ allele, and a 300-bp null allele. The primers for PCR genotyping of the Cre gene in K18-EGFP;K8/K18-CreER ${ }^{T}$ and Alb-Cre mice were Cre-1 (forward, 5'-GGACATGTTCAGGGATCGCCAGGCG-3') and Cre- $\beta$ (reverse, $5^{\prime}$-CGACGATGAAGCATGTTTAGCTG-3'), yielding a 230-bp product. The $R 26 R^{\text {lacZ/+ }}$ allele was detected by the primers Rosa- 1 (reverse, 5'-GCGAAGAGTTTGTCCTCAACC-3'), Rosa-2 (reverse, 5'-GGAGCGGGAGAAGATATG-3'), and Rosa-3 (forward, 5'-AAAGTCGCTCTGAGTTGTTAG-3'), yielding a 300-bp $R 26 R^{\text {lacZ/+ }}$ allele and a 550-bp wild-type allele.

\section{Tamoxifen Administration}

Tamoxifen (10 mg/mL; Sigma-Aldrich, St. Louis, MO) was dissolved in a 1:10 mixture of ethanol and sunflower seed oil (Sigma-Aldrich). Tamoxifen $(50 \mathrm{mg} / \mathrm{kg}$ ) was administrated intraperitoneally for 1 (one dose) or 3 (triple dose) consecutive days to 6-week-old mice. 
Histology, Sirius Red Staining, IHC, and IF Staining

Livers were fixed in $4 \%$ paraformaldehyde overnight and then embedded in paraffin or OCT compound (Tissue-Tek OCT; Sakura Finetek, Torrance, CA) for paraffin or frozen sectioning, respectively. The hematoxylin and eosin staining procedure was described previously. ${ }^{47}$ Basophilic cells in periportal areas of hematoxylin and eosin-stained liver sections were manually counted under high-power views. Sirius red staining was performed by the Taiwan Mouse Clinic, National Phenotyping and Drug Testing Center (Academia Sinica, Taipei, Taiwan). The Sirius red positively stained areas were quantified by ImageJ software version $1.48(\mathrm{NIH}$, Bethesda, MD; http://imagej.nih.gov/ij). For the immunohistochemical (IHC) analysis, antibodies against HNF4 $\alpha$ (sc-8987; 1:100; Santa Cruz Biotechnology, Santa Cruz, CA), K19 (TROMA-III; 1:400; Developmental Studies Hybridoma Bank, Iowa City, IA), F4/80 (ab6640; 1:400; Abcam, Cambridge, MA), CD3 (ab5690; 1:100; Abcam), B220 (number 166501; 1:100; SouthernBiotec, Birmingham, AL), IL- $\beta$ (ab9722; 1:100; Abcam), tumor necrosis factor (TNF)- $\alpha$ (ab6671; $1: 100$; Abcam), PTEN (number 9595; 1:100; Cell Signaling Technology, Danvers, MA), p-AKT (number 4058; 1:100; Cell Signaling Technology), Ki-67 (number 12202; 1:400; Cell Signaling Technology), epithelial cell adhesion molecule (EpCAM; G8. 8; 1:400; Developmental Studies Hybridoma Bank), A6 (A6 BCM; 1:100; Developmental Studies Hybridoma Bank), K8/ K18 (TROMA-1; 1:400; Developmental Studies Hybridoma Bank), and SOX9 (sc-20095; 1:400; Santa Cruz Biotechnology) were used. Positively stained cells in periportal areas detected by IHC were manually counted under high-power views. For immunofluorescence (IF) staining, liver sections were blocked by $10 \mathrm{mg} / \mathrm{mL}$ Sudan Black (Sigma-Aldrich) in $70 \%$ ethanol at room temperature overnight to reduce autofluorescence and then incubated with antibodies against $\beta$-galactosidase (55979; 1:1000; MP Biomedicals, Santa Ana, CA), EpCAM (Ab71916; 1:100; Abcam), or various antibodies described above. Quantification of co-IF data was manually counted under high-power views. Five tissue sections of each mouse (three to five mice from each genotype) were quantified.

\section{RNA Isolation and Real-Time Quantitative RT-PCR}

Total RNA content was extracted from frozen livers by TRIzol reagent (Thermo Fisher Scientific, Waltham, MA) and reverse transcribed to synthesize cDNA using the $\mathrm{Su}$ perScript III First-Strand Synthesis System (Thermo Fisher Scientific). Real-time PCR was performed using the Kapa SYBR Fast qPCR kit (Kapa Biosystems, Wilmington, MA). The primer sequences used for real-time quantitative RTPCR were Pten (forward, 5'-AGGCACAAGAGGCCCTAGAT-3'; reverse, 5'-CTGACTGGGAATTGTGACTCC-3'), Epcam (forward, 5'-CAGCTGGACACCGGCATT-3'; reverse, $5^{\prime}$-TGGACCTGCACCTATAAGACGTT- $3^{\prime}$ ), $I l 1 b$ (forward, 5'-AGTTGACGGACCCCAAAAG-3'; reverse, 5'-AGCTGGATGCTCTCATCAGG-3'), Tnf (forward, 5' CAGCCTCTTCTCATTCCTGCTTGTG- $3^{\prime}$; reverse, 5' CTGGAAGACTCCTCCCAGGTATAT- $3^{\prime}$ ), Il6 (forward, 5'-TAGTCCTTCCTACCCCAATTTCC-3'; reverse, 5'TTGGTCCTTAGCCACTCCTTC-3'), and Actb (actin, $\beta$; forward, 5'-CTAAGGCCAACCGTGAAAAG-3'; reverse, 5'-ACCAGAGGCATACAGGGACA-3').

\section{Western Blot Analysis}

Total protein extracted from frozen livers with lysis buffer [50 $\mathrm{mmol} / \mathrm{L} \mathrm{Tris}-\mathrm{HCl}$ (pH 7.9), $150 \mathrm{mmol} / \mathrm{L} \mathrm{NaCl}, 0.1 \%$ SDS, $1 \%$ NP-40, $0.5 \%$ sodium deoxycholate, protease inhibitor cocktail (Roche Applied Science, Indianapolis, IN), and phosphatase inhibitor cocktail (Sigma-Aldrich)] was subjected to Western blot analysis. Primary antibodies against PTEN (number 9595; 1:1000; Cell Signaling Technology), p-AKT ${ }^{\mathrm{S} 473}$ (number 4058; 1:1000; Cell Signaling Technology), $\beta$-actin (A5441; 1:5000; Sigma-Aldrich), pan-AKT (number 4691; 1:1000; Cell Signaling Technology), IL-1 $\beta$ (ab9722; 1:1000; Abcam), and TNF- $\alpha$ (ab6671; 1:1000; Abcam) were used.

\section{Fluorescence-Activated Cell Sorting}

Livers were dissected and further digested with $0.012 \%$ type III collagenase (Worthington Biochemical Corp., Lakewood, $\mathrm{CO})$ and DNaseI (1:1000; Sigma-Aldrich) at $37^{\circ} \mathrm{C}$ for 30 minutes. Enzymatic digestion was then blocked with collagenase blocking buffer ( $1 \%$ bovine serum albumin and $5 \mathrm{mmol} / \mathrm{L}$ EDTA/phosphate-buffered saline), and cells were washed, suspended in $1 \times$ phosphate-buffered saline, and passed through cell strainers with 70 - and $40-\mu \mathrm{m}$ pore sizes (BD Falcon, San Jose, CA). Dissociated single cells were incubated with PEcy7-conjugated anti-EpCAM (118215; 1:300; Biolegend, San Diego, CA), phosphatidylethanolamine-conjugated anti-CD133 (141203; 1:200; Biolegend), and APC-conjugated anti-CD45 (103112; 1:400; Biolegend) antibodies at $4^{\circ} \mathrm{C}$ for 30 minutes. Stained cells were analyzed and sorted with a BD FACSAria sorter (BD Biosciences, San Jose, CA).

\section{Sphere-Forming Assay}

A total of 10,000 isolated $\mathrm{CD} 133^{+} \mathrm{EpCAM}^{+} \mathrm{CD} 45^{-}$cells were mixed with $50 \mu \mathrm{L}$ of Matrigel and plated in 12-well plates. Culture medium was added after polymerization of the Matrigel. The culture medium was composed of Dulbecco's modified Eagle's medium/F12 medium (Thermo Fisher Scientific) supplemented with $1 \times$ B27 (Thermo Fisher Scientific), $1 \times$ N2 (Thermo Fisher Scientific), $20 \mathrm{ng} / \mathrm{mL}$ epidermal growth factor (ScienCell, Carlsbad, CA), $50 \mathrm{ng} / \mathrm{mL}$ basic fibroblast growth factor (Peprotech, Rocky Hill, NJ), and $50 \mathrm{ng} / \mathrm{mL}$ human growth factor (Peprotech). Images of spheres under an inverted microscope (imt-2; Olympus, Tokyo, Japan) were taken on day 10 after plating. 


\section{X-Gal Staining}

Whole-mount X-Gal staining of livers was conducted as previously described. ${ }^{49}$ Post-fixed X-Gal-stained sections were counterstained with nuclear fast red (Muto Pure Chemicals, Tokyo, Japan), as described previously. ${ }^{50}$

\section{Statistical Analysis}

Statistical analysis was performed using paired $t$-tests. Data are shown as means $\pm \mathrm{SD}$. Statistical significance was set at $P<0.05$.

\section{Results}

Pten Haplodeficiency Accelerates Mir122a-Null Liver Tumorigenesis

To address whether Pten collaborates genetically with Mirl22a in liver tumorigenesis, Mirl22 $a^{-/-} ;$Pten $^{+/-}$mice were generated to monitor their hepatic tumor acceleration in comparison with liver tumor development in Mirl22a $a^{-1}$ mice. At 6 to 9 months, the Mirl22a ${ }^{+/-} ;$Pten $^{+/-}$(nine males and eight females at 6 months of age; two males and two females at 9 months of age) and Mir122a $a^{-/-}$(eight males and
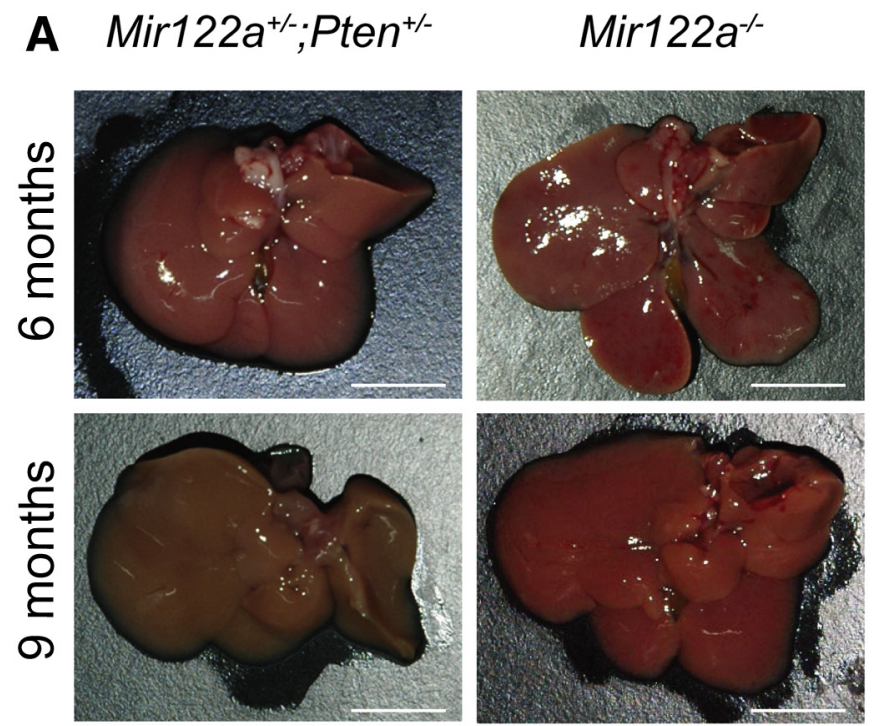

B

Mir122a $^{-/} ;$Pten $^{+-}$
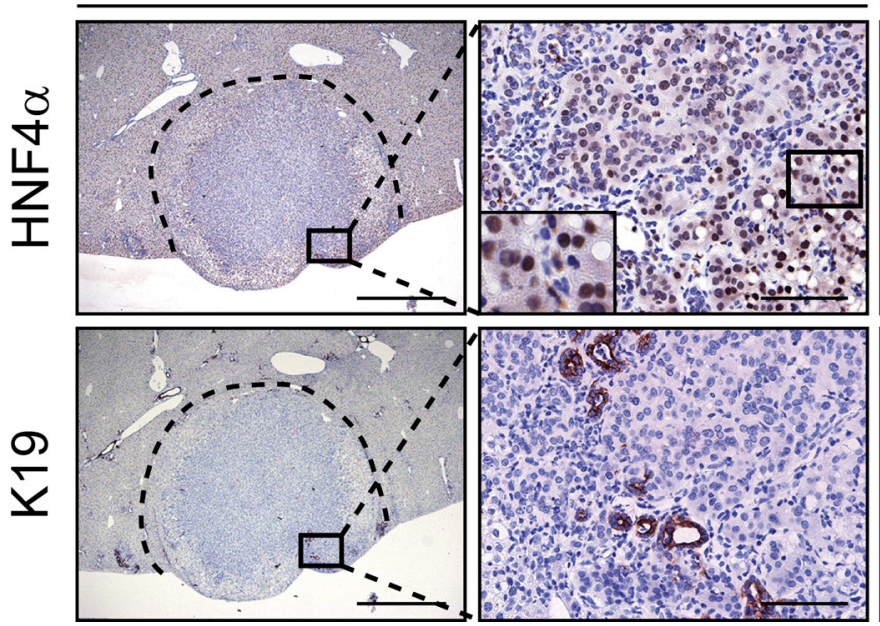

Mir122a $^{-/-} ;$Pten $^{+-}$
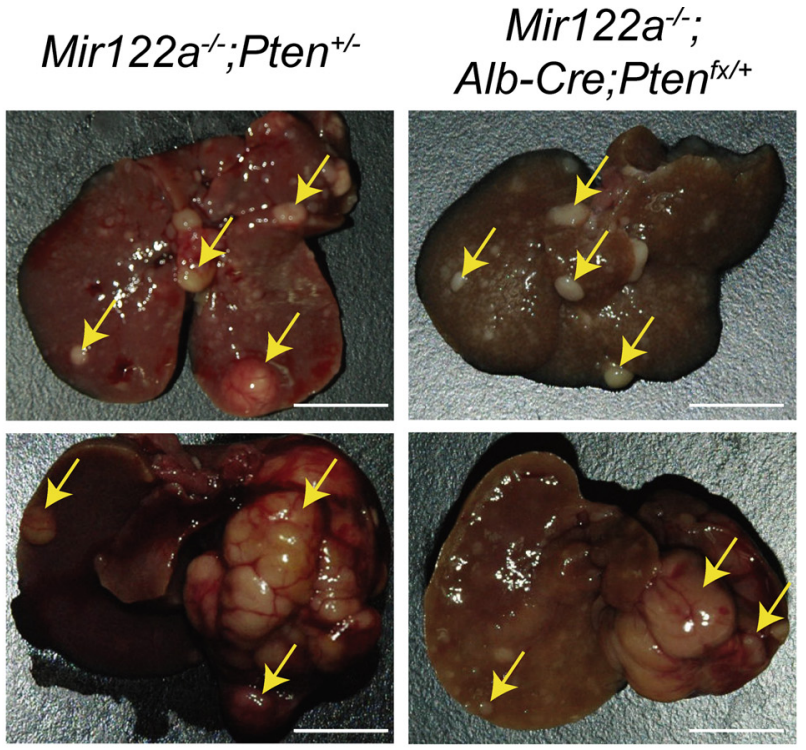

Mir122a-; Alb-Cre;Pten ${ }^{f \times t+}$

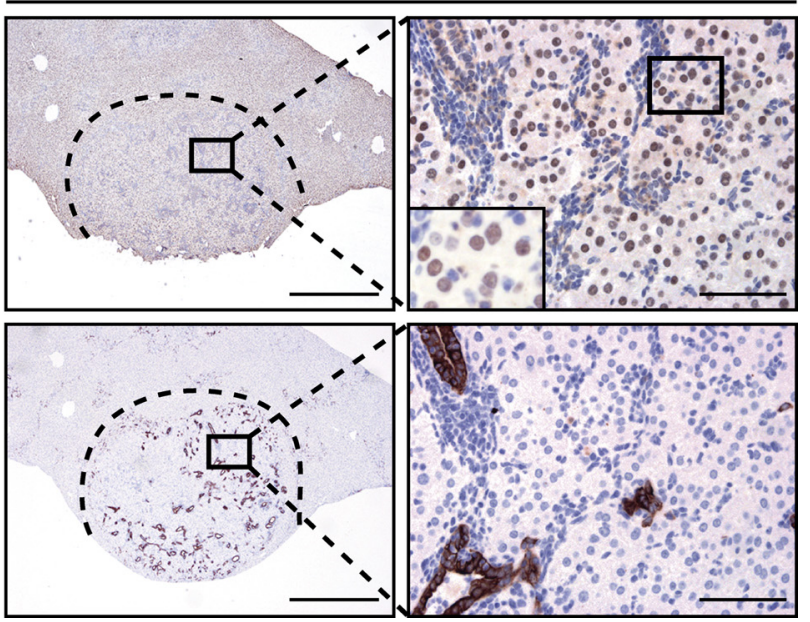

Figure 1 Monoallelic Pten deletion accelerates Mir122a-deficient tumorigenesis. A: Liver gross views of Mir122a ${ }^{+/-} ;$Pten $^{+/-}$, Mir122a $^{-/-}$, Mir122a $^{-/-}$; Pten $^{+/-}$, and Mir122a $a^{-/-} ;$Alb-Cre;Pten ${ }^{f x /+}$ mice at 6 and 9 months of age. Yellow arrows indicate macroscopic tumors observed in the Mir122a ${ }^{-/-} ;$Pten $^{+/-}$ livers and Mir122a $a^{-1-} ; A l b$-Cre;Pten ${ }^{f x /+}$ livers. B: Immunohistochemistry reveals expression of the hepatocyte marker HNF4 $\alpha$ and cholangiocyte marker keratin 19 (K19) in hepatic adenomas developed in Mir122a $a^{-/} ;$Pten $^{+/-}$and Mir122a $a^{-/-} ;$Alb-Cre;Pten ${ }^{f x /+}$, respectively, in 6-month-old mice. The dashed curved lines depict tumor boundaries. Boxed areas in images in the first and third columns are shown at higher magnification in the images in the second and fourth columns; boxed areas in images in the top row of the second and fourth columns are shown at higher magnification in the insets. Scale bars: 1 cm (A); $1 \mathrm{~mm}$ (B, first and third columns); $100 \mu \mathrm{m}$ (B, second and fourth columns). 
11 females at 6 months of age and two males and two females at 9 months of age) mice showed no sign of hepatic tumors. Interestingly, approximately $47 \%$ of 6 -month-old (eight of 18 males and six of 12 females) and $80 \%$ of 9-month-old (two of three males and two of two females) Mirl22a $^{-/} ;$Pten $^{+/-}$mice developed multiple liver tumors (Figure 1A; Table 1). In addition, Mir122a ${ }^{-/-} ; A l b$ Cre;Pten ${ }^{f x+}$ mice were generated, in which the monoallelic Pten was specifically deleted in the hepatocytes in the Mir122a-null background. Hepatic nodules and manifest liver tumors were consistently observed in all Mirl22 $a^{-1-} ;$ Alb-Cre;Pten ${ }^{f x /}$ mice at 6 and 9 months of age (two males and one female at each time point) (Figure 1A; Table 1). In these tumor-bearing mice, metastasis was not observed. IHC data revealed that most tumor cells expressed the hepatocyte marker HNF4 $\alpha$ in Mir122a ${ }^{-/-} ;$Pten $^{+/-}$and Mir122a $a^{-/-} ;$Alb-Cre;Pten ${ }^{f x+}$ tumors (Figure 1B). A small proportion of tumor cells expressed K19, which formed ductal or acinar arrangements embedded within Mirl22 $^{-/-} ;$Pten $^{+/-}$and Mirl22a ${ }^{-/-} ;$Alb-Cre $;$Pten $^{f x+}$ tumors (Figure 1B). Overall, our results demonstrate that monoallelic Pten loss facilitates hepatocellular adenoma and carcinoma development in Mir122a-null mice at 6 and 9 months of age.

Inflammation and Fibrosis in Mir122a $a^{--}$, Mir122a $^{-/-}$; Pten $^{+/-}$, and Mir122a $a^{-/-} ;$Alb-Cre;Pten ${ }^{f x /+}$

Premalignant Livers

Hematoxylin and eosin staining revealed expanding basophilic cells residing in the periportal areas of Mirl22a $a^{-/-}$and Mirl22a $^{-1-} ;$ Pten $^{+/-}$premalignant livers at 6 months of age (Figure 2A). More prominent basophilic lesions, including larger oval nuclear cells and small round immune cells, were identified in the premalignant livers of $\mathrm{Mirl}_{22 a^{-1}} ; \mathrm{Pten}^{+/-}$ mice than in the Mirl22a $a^{-1-}$ mice at 6 months of age (Figure 2A). Quantitative results showed that the larger basophilic cells were significantly increased in the periportal areas of Mirl22a $^{-1-} ;$ Pten $^{+/-}$livers and, to a lesser extent, in Mirl22a $a^{-1-}$ livers, compared with those of Mirl22a $^{+/-} ;$Pten $^{+/-}$livers (Figure 2A). Macrophages, T cells, and $\mathrm{B}$ cells residing at the basophilic lesions were identified by the macrophage marker F4/80, the T-cell marker CD3, and the pan B-cell marker B220, respectively (Figure 2B). Many F4/80stained macrophages surrounded the ductular reactive cells in Mirl22a ${ }^{-/-} ;$Pten $^{+/-}$premalignant livers and were also scattered at the parenchyma of Mirl22a ${ }^{+/-} ;$Pten $^{+/-}$, Mirl22a $^{-/-}$, and Mirl22a ${ }^{-1} ;$ Pten $^{+/-}$livers (Figure 2B). More CD3- and B220-positive cells were detected in the periportal lesions of

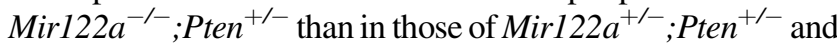
Mir122a $a^{-/-}$livers (Figure 2B), indicating higher levels of

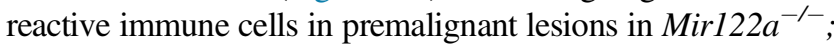
$\mathrm{Pten}^{+/-}$livers. Consistently, infiltrating macrophages and lymphocytes were also increased in premalignant livers of Mir122a ${ }^{-/-}$;Alb-Cre;Pten ${ }^{f x+}$ mice compared with those in their littermate controls (Supplemental Figure S1). mRNA
Table 1 Liver Tumor Incidence of Mir122a $a^{-/-} ;$Pten $^{+/-}$and Mir122a $^{-/-} ;$Alb-Cre;Pten ${ }^{f x /+}$ Mice

\begin{tabular}{|c|c|c|c|}
\hline \multirow[b]{2}{*}{ Genotype } & \multirow[b]{2}{*}{ Sex } & \multicolumn{2}{|c|}{$\begin{array}{l}\text { Tumor incidence by age, } \\
\text { months }\end{array}$} \\
\hline & & 6 & 9 \\
\hline \multirow[t]{2}{*}{ Mir122 $^{+/-} ;$Pten $^{+/-}$} & M & $0 / 9(0)$ & $0 / 2(0)$ \\
\hline & $\mathrm{F}$ & $0 / 8(0)$ & $0 / 2(0)$ \\
\hline \multirow[t]{2}{*}{ Mir122a $a^{-/-}$} & M & $0 / 8(0)$ & $0 / 2(0)$ \\
\hline & $\mathrm{F}$ & $0 / 11(0)$ & $0 / 2(0)$ \\
\hline \multirow[t]{2}{*}{ Mir122a $a^{-/-} ;$Pten $^{+/-}$} & M & $8^{*} / 18(44)$ & $2^{\dagger} / 3(67)$ \\
\hline & $\mathrm{F}$ & $6^{*} / 12(50)$ & $2^{\dagger} / 2(100)$ \\
\hline \multirow[t]{2}{*}{ Mir122 ${ }^{+/-} ;$Alb-Cre;Pten ${ }^{f x /+}$} & M & $0 / 3(0)$ & $0 / 2(0)$ \\
\hline & $\mathrm{F}$ & $0 / 2(0)$ & $0 / 2(0)$ \\
\hline \multirow[t]{2}{*}{ Mir122a $a^{-/-} ; A l b-C r e$} & M & $0 / 3(0)$ & $0 / 3(0)$ \\
\hline & $\mathrm{F}$ & $0 / 2(0)$ & $0 / 2(0)$ \\
\hline \multirow[t]{2}{*}{ Mir122a $a^{-/-} ; A l b-C r e ;$ Pten $^{f x /+}$} & M & $2^{*} / 2(100)$ & $2^{\dagger} / 2(100)$ \\
\hline & $\mathrm{F}$ & $1^{*} / 1(100)$ & $1^{\dagger} / 1(100)$ \\
\hline
\end{tabular}

Data are given as number/total (percentage).

*Hepatic adenoma-bearing mice.

${ }^{\dagger} \mathrm{HCC}$-bearing mice.

$F$, female; $M$, male.

levels of proinflammatory cytokines were examined, and it was found that $I l l b$ and Tnf, but not $I l 6$, were significantly increased in both Mirl22a ${ }^{-/} ;$Pten $^{+/-}$and Mir122a ${ }^{-/} ; A l b-$ Cre;Pten ${ }^{f x /}$ livers compared with those in other groups $\left(\right.$ Mirl22a $^{+/-} ;$Pten $^{+/-}$, Mirl22a ${ }^{-/-}$, Mirl22a ${ }^{+/-} ;$Alb-Cre;Pten $^{f x++}$, and Mir122a $a^{-/-} ;$Alb-Cre;Pten ${ }^{+/+}$) (Figure 2, C and D). Using IHC to assess IL- $1 \beta$ and TNF- $\alpha$ positivity in situ, both IL-1 $\beta$ - and TNF- $\alpha$-positive cells could be detected in Mirl22a $a^{-/-}$livers and were highly increased in Mirl22a $a^{-1-}$; $\mathrm{Pten}^{+/-}$periportal areas (Supplemental Figure S2, A-D). IL-1 $\beta$ was found to be slightly increased in Mirl22a ${ }^{-/-}$livers and further up-regulated in Mirl22a ${ }^{-/-} ; \mathrm{Pten}^{+/-}$whole-liver lysates by Western blot analysis (Supplemental Figure S2, E and F). However, using Western blot analysis, the protein levels of TNF- $\alpha$ were unable to be detected, which might be attributable to a low percentage of TNF- $\alpha$-positive cells in whole-liver lysates (Supplemental Figure S2E). In parallel, the inflammatory phenotypes, including the percentages of IL$1 \beta-$ and TNF- $\alpha$-positive cells, as well as the protein levels in Mirl22a $a^{-1-} ;$ Alb-Cre;Pten ${ }^{f x+}$ livers, were also significantly increased compared with those of Mirl22a ${ }^{-/-}$; Alb-Cre $;$ Pten $^{+/+}$and Mir122a ${ }^{+/-} ;$Alb-Cre;Pten ${ }^{f x /+}$ livers (Supplemental Figure S3). In addition to the inflammatory phenotypes, prominent Sirius red positive-stained areas were observed and quantified in Mirl22a ${ }^{-/} ;$Pten $^{+/-}$livers compared with the Mirl22a ${ }^{+/-} ;$Pten $^{+/-}$and Mirl22a ${ }^{-/-}$livers (Figure 2, E and F), indicating more fibrotic lesions. Similarly, Sirius red-positive areas were also greater in the Mirl22a ${ }^{-/-}$; Alb-Cre;Pten ${ }^{f x /+}$ livers than their controls (Supplemental Figure S4). These data indicate that inflammation and fibrosis occurred earlier in Mirl22a ${ }^{-/-}$Pten $^{+/-}$and Mir122a ${ }^{-/-} ;$Alb-Cre;Pten ${ }^{f y+}$ livers and promoted liver tumor progression. 
PTEN Down-Regulation, AKT Phosphorylation, and Cellular Proliferation in Mir122a $a^{-/-} ;$Pten $^{+/-}$ Premalignant Livers and Tumors

It is likely that expression of monoallelic Pten may be downregulated in the Mir $122 a^{-/} ;$Pten $^{+/-}$hepatocytes, resulting in the subsequent loss of tumor-suppressive function that could lead to HCC initiation. Thus, PTEN and p-AKT ${ }^{\mathrm{S} 473}$ levels were examined in the liver samples of controls, Mir122a ${ }^{-/-}$, and $\mathrm{Mirl}_{22 a^{-/}} ; \mathrm{Pten}^{+/-}$mice, and liver tumors of Mir122a ${ }^{-/-} ;$Pten $^{+/-}$mice at 6 months of age. Using Western blot analysis, PTEN protein levels were found to be comparable in Pten $^{+/-}$and Mirl22a ${ }^{-/-} ;$Pten $^{+/-}$liver samples (Figure 3, A and B). Down-regulated PTEN and increased p-AKT ${ }^{\mathrm{S} 473}$ were only specifically detected in Mirl22a $a^{-/}$; $\mathrm{Pten}^{+/-}$liver tumors (Figure 3, A and B). We hypothesized that down-regulated PTEN and a lack of detectable level of p$\mathrm{AKT}^{\mathrm{S} 473}$ in the Mir122a $a^{-1} ;$ Pten $^{+/-}$premalignant livers may occur locally in a subpopulation, so the changes of PTEN and $\mathrm{p}-\mathrm{AKT}^{\mathrm{S} 473}$ cannot be detected in the whole-liver lysates used in Western blot analysis. Therefore, PTEN and $\mathrm{p}-\mathrm{AKT}^{\mathrm{S}} 473$ were examined using IHC, and it was found that the cells with PTEN down-regulation and AKT phosphorylation were specifically detected in the periportal reactive areas (Figure 3C). Cellular proliferation was further examined in Mirl22a ${ }^{+/}$; Pten $^{+/-}$, Mirl22a $a^{-/-}$, and Mirl22a $a^{-/} ;$Pten $^{+/-}$livers. The Ki-67-stained sections exhibited a highest level of proliferative cells in periportal areas of Mirl22a ${ }^{-/-} ;$Pten $^{+/-}$premalignant livers than that in Mirl22a $a^{-1-}$ and Mirl22a $a^{+/-}$; Pten $^{+/-}$livers (Figure 3, D and E). Because the infiltrating immune cells were identified in periportal areas and associated with higher levels of IL-1 $\beta$ and TNF- $\alpha$ in Mir122a $a^{-/}$; $\mathrm{Pten}^{+/-}$livers (Supplemental Figure S2, A-D), the possibility of IL-1 $\beta-$ and/or TNF- $\alpha-$ mediated NF- $\kappa$ B activation (nuclear localization) was examined in control, Mirl22a ${ }^{-/-}$, and Mir122a ${ }^{-/-} ;$Pten $^{+/-}$livers. Higher nuclear staining of NF- $\kappa \mathrm{B}$ was observed in the periportal areas of Mirl22a ${ }^{-/} ;$Pten $^{+/-}$ premalignant livers than in the periportal areas of Mirl22a $a^{-1-}$ premalignant livers (Supplemental Figure S5). As shown by the early reports, ${ }^{51-53}$ activation of NF- $\kappa \mathrm{B}$ could exhibit antagonistic effects to down-regulate PTEN levels. Thus, our findings imply that the down-regulated PTEN in periportal areas of Mirl22a ${ }^{-/-}$Pten $^{+/-}$premalignant livers is likely to be associated with the inflammatory microenvironments, as shown by the elevated levels of IL-1 $\beta / \mathrm{TNF}-\alpha$ and local activation of NF- $\kappa \mathrm{B}$.

\section{Expansion of Oval Cells in Mir122a $a^{-/-}$and Mir122a $a^{-/-}$; Pten $^{+/-}$Premalignant Livers}

To examine the characteristics of periportal lesions in Mir122a ${ }^{-/-} ;$Pten $^{+/-}$livers, ductular reaction was examined using biliary or oval cell markers (A6, EpCAM, and K19) in immunostaining, and these markers were found to be expressed in the periportal basophilic cells in Mir122a $a^{-/-}$and Mir122a $^{-/-}$Pten $^{+/-}$premalignant livers (Figure 4A). The ductular reaction was more prominent in $\mathrm{Mirl}_{22} \mathrm{a}^{-/-}$, $\mathrm{Pten}^{+/-}$than in Mirl22a $a^{-/}$premalignant livers (Figure 4A). Similar biliary/oval cell markers A6 and K19 were also expressed in the periportal basophilic cells in $\mathrm{Mir}_{22} 2 a^{-/-} ; \mathrm{Alb}$ Cre;Pten ${ }^{f x+}$ livers (Supplemental Figure S6). Coimmunofluorescence staining was performed, and it was found that EpCAM levels with K19 and A6 were coexpressed in cholangiocytes of the control Mirl22 $a^{+/-} ;$Pten $^{+/-}$livers and in oval cells of Mirl22a $a^{-/}$and Mirl22a ${ }^{-/-} ;$Pten $^{+/-}$premalignant livers, respectively (Supplemental Figure S7, A and B). Real-time quantitative RT-PCR data confirmed that the expression of Epcam was significantly up-regulated in Mir122a $a^{-/-}$livers and more profoundly up-regulated in Mir122a $^{-/-} ;$Pten $^{+/-}$premalignant livers (Figure 4B). Flow cytometry analysis to detect EpCAM protein on the cell surface also revealed increased EpCAM-positive cells in Mir122a ${ }^{-/-} ;$Pten $^{+/-}$premalignant livers (Supplemental Figure S7, C and D). A previous study has identified expanded $\mathrm{CD} 133^{+} \mathrm{CD} 45^{-}$oval cells as liver bipotent progenitors and cancer-initiating cells in the hepatocyte-specific Pten deletion mouse model. ${ }^{33}$ In this study, $\mathrm{CD} 133^{+}$populations were further quantified by flow cytometry using $\mathrm{CD} 133^{+} \mathrm{EpCAM}^{+}$in CD45 negatively gated cells of control, Mirl22a $a^{-1-}$, and Mir122a $a^{-1-} ;$ Pten $^{+/-}$livers. A trend toward increased numbers of $\mathrm{CD} 133^{+} \mathrm{EpCAM}^{+} \mathrm{CD} 45^{-}$cells was found in Mir122a ${ }^{-/-} ;$Pten $^{+/-}$livers compared with that in Mir122a $a^{-1-}$ livers (Supplemental Figure S8). Next, it was examined whether $\mathrm{CD}_{133^{+}} \mathrm{EpCAM}^{+} \mathrm{CD} 45^{-}$cells in Mir122a $^{-/-} ;$Pten $^{+/-}$livers exhibited anchorage-independent sphere-forming ability. Indeed, it was found that the sphereforming ability of $\mathrm{CD}_{133}{ }^{+} \mathrm{EpCAM}^{+} \mathrm{CD} 45^{-}$cells was higher in Mir122a ${ }^{-/-} ;$Pten $^{+/-}$livers compared with Mir122a $a^{-/-}$livers (Figure 4, C and D). The size of spheres, however, was comparable among different genotypes (Figure 4E). Our data indicate that the expansion of $\mathrm{CD}_{133}{ }^{+} \mathrm{EpCAM}^{+} \mathrm{CD}_{4} 5^{-}$progenitor cells in the Mir122a ${ }^{-/-}$; $\mathrm{Pten}^{+/-}$livers was correlated with PTEN down-regulation and exhibited anchorage-independent sphere-forming ability.

\section{Aberrant K8-Stained Patterns Associated in Periportal Areas of Mir122 $a^{-/-} ;$Pten $^{+/-}$Premalignant Livers}

$\mathrm{K} 8$ and $\mathrm{K} 18$ have been used to identify ductular reactive cells in human liver diseases. ${ }^{36}$ Using IHC, K8 expression was detected by TROMA-I monoclonal antibody in sections of

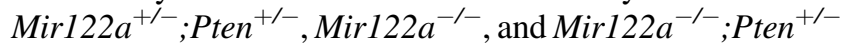
livers. K8 was highly expressed in the biliary ducts in the Mirl22a ${ }^{+/} ;$Pten $^{+/-}$and ductular reactive cells in Mirl22a $a^{-/}$and Mir122a ${ }^{-/-}$Pten $^{+/-}$livers (Figure 5A). Strikingly, the hepatic parenchyma of Mirl22 ${ }^{-/-} ; \mathrm{Pten}^{+/-}$ premalignant livers revealed heterogeneous patterns with high, intermediate, and low K8-staining intensities (Figure 5A). The intermediate-stained K8 cells, referred to as $\mathrm{K} 8^{\text {int }}$ cells, were round and larger hepatocyte-like cells, which were apparently unlike the highly intense K8-stained ductular cells (hereafter referred to as $\mathrm{K} 8^{\text {hi }}$ cells) in Mirl22 $a^{-1-}$; 

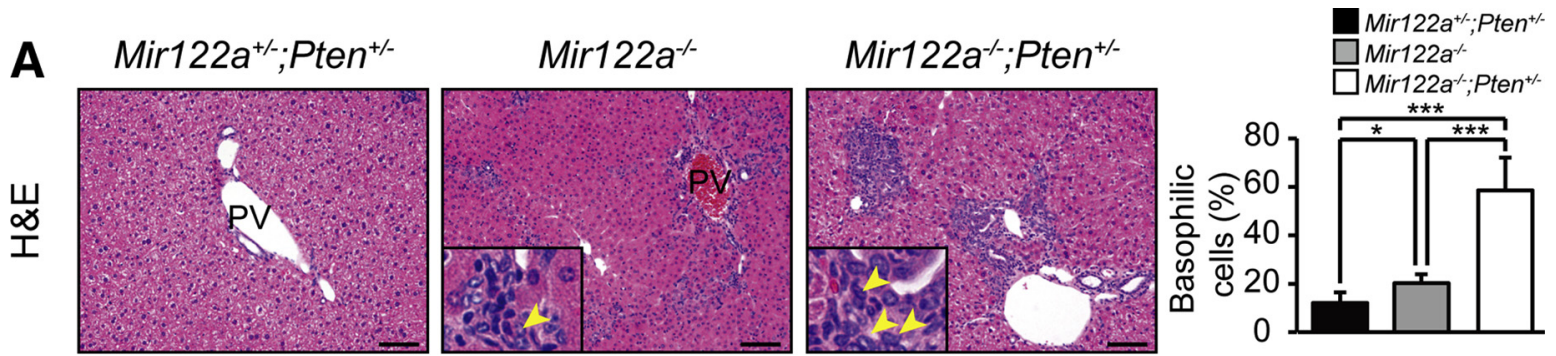

B $\mathrm{Mir122a}^{+/} ; \mathrm{Pten}^{+/-}$

Mir122a ${ }^{--}$
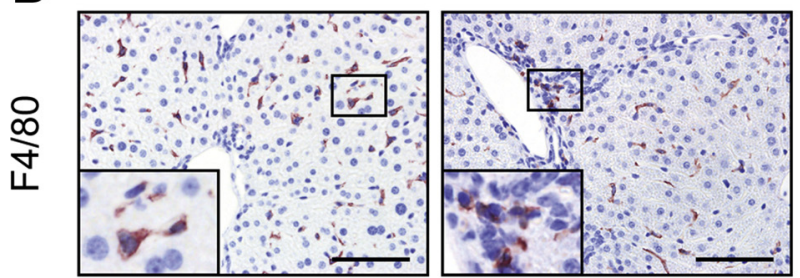

Mir122a $^{-/-} ;$Pten $^{+/-}$
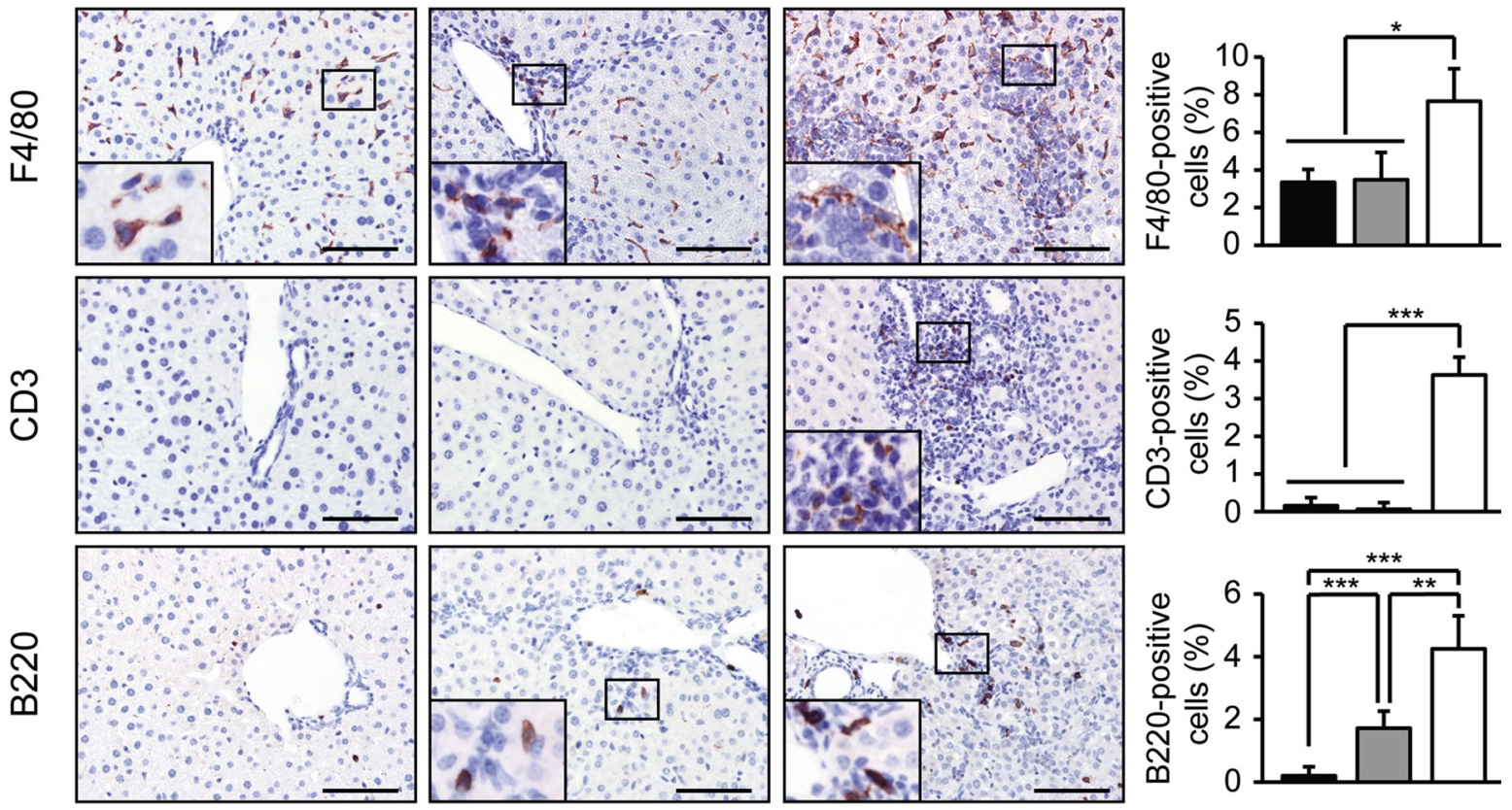

C
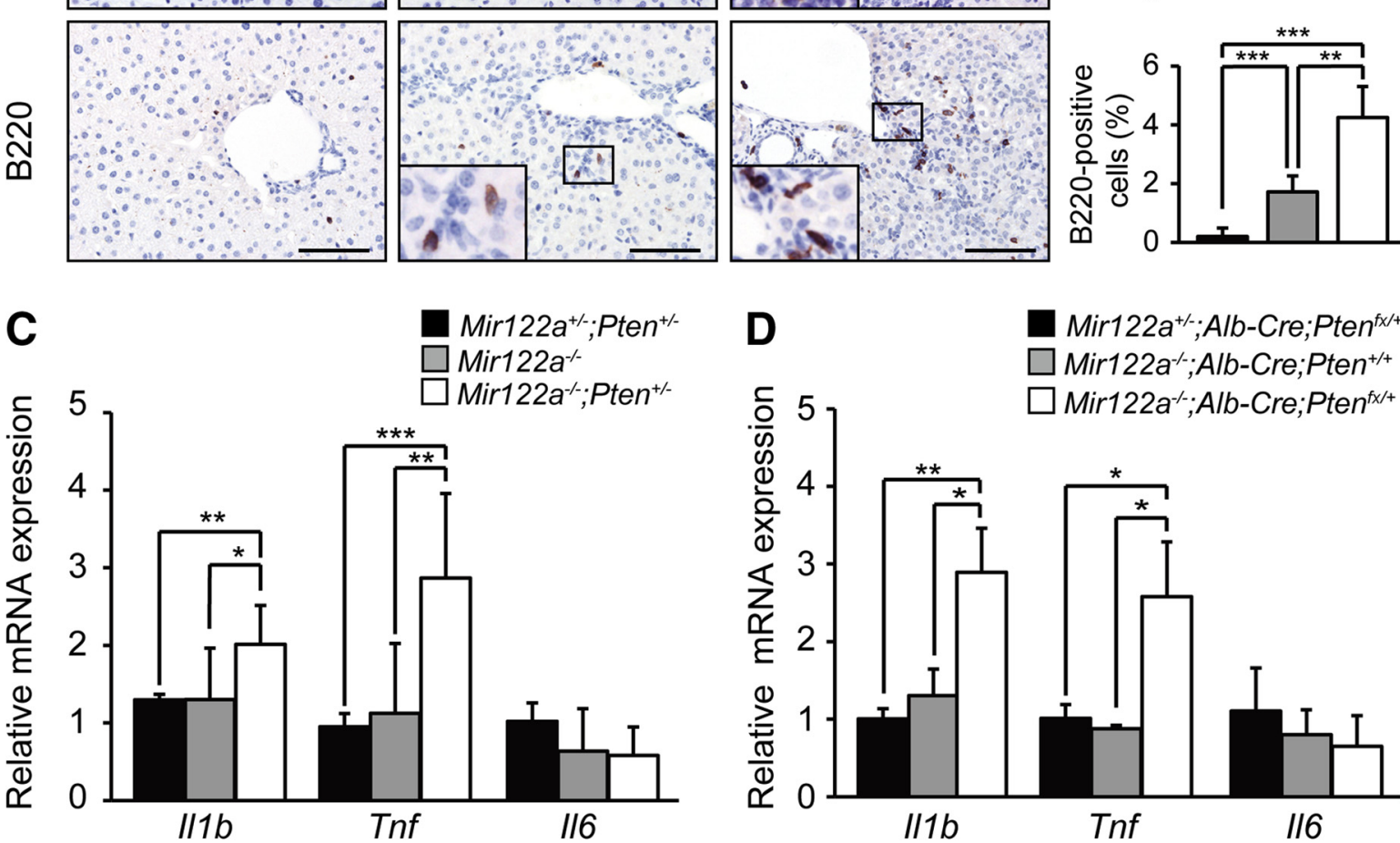

E

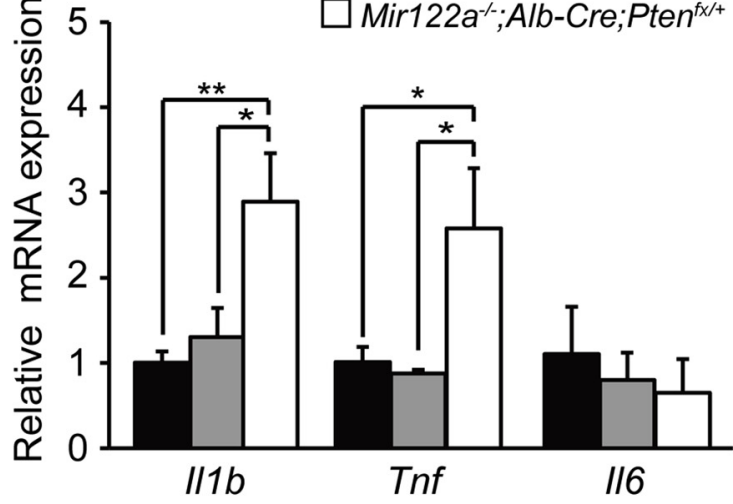
Mir122a $a^{+/} ;$Pten $^{+-}$

Mir122a-

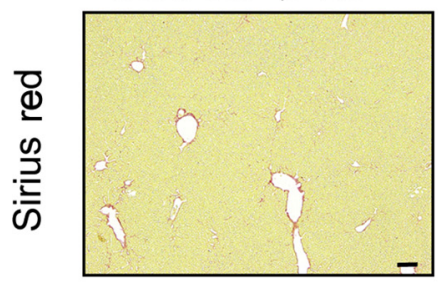
Mir122a $a^{-/} ;$Pten $^{+/-}$

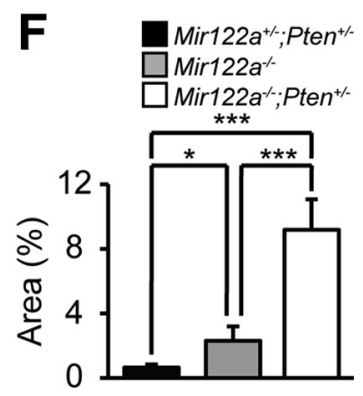


Pten $^{+/-}$premalignant livers (Figure 5A). Co-IF staining of

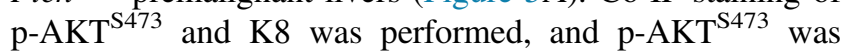
detected in both $\mathrm{K} 8^{\text {hi }}$ and $\mathrm{K} 8^{\text {int }}$ cells in the periportal area of Mirl22a ${ }^{-1-} ;$ Pten $^{+/-}$livers (Figure 5B). To characterize the cellular identity of $\mathrm{K} 8^{\text {int }}$ cells, hepatocyte differentiation marker HNF4 $\alpha$ was costained with K8 in the sections of Mirl22a ${ }^{+/-} ;$Pten $^{+/-}$, Mirl22a $^{-/-} ;$and Mirl22a $a^{-/} ;$Pten $^{+/-}$ livers. Only $\mathrm{K} 8^{\text {int }}$ cells were $\mathrm{HNF} 4 \alpha$ positively stained hepatocytes in the periportal area of Mir122a ${ }^{-/-} ;$Pten $^{+/-}$livers, whereas $\mathrm{K} 8^{\text {hi }}$ cells were $\mathrm{HNF} 4 \alpha$ negatively stained ductular cells in all samples (Figure 5C). Quantification data showed slightly increased $\mathrm{K}^{\text {int }}$ and $\mathrm{HNF} 4 \alpha$ double-positive cells in the Mirl22a $a^{-1-}$ premalignant livers and greatly increased Mir122a ${ }^{-1-} ;$ Pten $^{+-}$in premalignant livers (Figure 5D). Interestingly, the aberrant $\mathrm{K} 8^{\mathrm{int}}$ cells were significantly increased and located next to $\mathrm{K} 8{ }^{\text {hi }}$ cells, which is indicative of a cell-lineage relationship between $\mathrm{K} 8{ }^{\text {hi }}$ and $\mathrm{K} 8^{\text {int }}$ cells in the periportal area of Mir122a $a^{-/-}$Pten $^{+/-}$livers.

SOX9 and K8 expression was examined using dual-colored IHC on the sections of Mirl22a ${ }^{+/-} ;$Pten $^{+/-}$, Mirl22a $^{-/-}$, and Mirl22 $a^{-/-} ;$Pten $^{+/-}$livers. SOX9 was coexpressed with some $\mathrm{K} 8^{\text {hi }}$ cells in the periportal areas of Mirl22a ${ }^{+/-} ; \mathrm{Pten}^{+/-}$, Mirl22a $^{-/-}$, and Mir122a $a^{-1} ;$ Pten $^{+/-}$livers (Figure 5E). Interestingly, SOX9 was also present in hepatocyte-like $\mathrm{K} 8{ }^{\text {int }}$ cells in Mir122a ${ }^{-/-} ;$Pten $^{+/-}$periportal areas (Figure 5E). It was further confirmed that SOX9 was coexpressed with HNF4 $\alpha$ specifically in Mirl22a ${ }^{-/-} ;$Pten $^{+/-}$livers, but not in Mirl22a $a^{-1-}$ livers (Figure 5F). These data indicate that the expanded $\mathrm{K} 8^{\text {int }}$ hepatocyte-like cells in the periportal areas of Mir122a ${ }^{-/-}$Pten $^{+/-}$livers included SOX9 ${ }^{+} \mathrm{HNF} 4 \alpha^{+}$hybrid hepatocytes.

\section{Tracing of $\mathrm{K}^{\text {hi }}$ and $\mathrm{K} 8^{\text {int }}$ Cells in Mir122a ${ }^{-/-}$;Pten ${ }^{+/-}$ Livers}

Lineage-tracing experiments were performed to examine whether $\mathrm{K}^{\mathrm{hi}}$ or $\mathrm{K} 8^{\text {int }}$ cells in Mirl22 $a^{-1-}$; Pten $^{+/-}$livers are the cells of origin for liver tumorigenesis. Previously, we generated a transgenic mouse $T g(K r t 18-E G F P, \quad K r t 8-$ $\mathrm{CreER}^{T 2}$ ) (hereafter referred to as K8-CreER) carrying $E G F P$ and $C r e E R^{T}$ transgenes driven by $\mathrm{K} 18$ and $\mathrm{K} 8$ promoters, respectively. ${ }^{46,47}$ K8-CreER; $R 26 R^{\text {LacZ } /+ \text {; }}$ Mirl22a $a^{-1-} ;$ Pten $^{+/-}$mice, which carried K8-CreER and
Rosa26 Cre LacZ reporter $\left(R 26 R^{\text {LacZ/+ }}\right)$ transgenes in Mirl22a ${ }^{-/-} ;$Pten $^{+/-}$backgrounds, were generated. Two different induction protocols (administration of either a single dose or a triple dose of tamoxifen) were examined, and $\mathrm{LacZ}$ reporter expression was analyzed in $K 8-C r e E R ; R 26 R^{L a c Z} /+$; Mirl22a ${ }^{-1-} ;$ Pten $^{+-}$premalignant livers at 1,8 , and 30 weeks after tamoxifen administration (Figure 6A). We hypothesized that a one-dose tamoxifen administration would induce Cre activity only in $\mathrm{K} 8^{\text {hi }}$ cells, whereas a triple-dose tamoxifen administration would be able to induce Cre activity in both $\mathrm{K} 8{ }^{\mathrm{hi}}$ and $\mathrm{K} 8^{\mathrm{int}}$ cells, for tracing their derivatives in K8-CreER;R26R ${ }^{\mathrm{LaCZ} /+} ; \mathrm{Mirl}_{22} \mathrm{a}^{-/-} ; \mathrm{Pten}^{+/-}$premalignant livers and tumors (Figure 6A). Compared with the X-Galstained livers 1 week after tamoxifen treatments, the result showed that a higher X-Gal-stained intensity was observed in the 8-week trace for K8-CreER;R26R ${ }^{\mathrm{LaCZ} /+}$;Mirl22a ${ }^{-/-}$; $\mathrm{Pten}^{+/-}$livers after one- or triple-dose tamoxifen treatments (Figure 6B). Co-IF staining using antibodies against K8 and $\beta$-galactosidase showed that $\beta$-galactosidase was only expressed in $\mathrm{K} 88^{\mathrm{hi}}$ cells in K8-CreER;R26R ${ }^{\mathrm{LacZ} /+}$; Mirl22a $^{-/-} ;$Pten $^{+-}$periportal areas at 1 week after the one-dose tamoxifen administration (Figure 6C). At 8 weeks after the one-dose tamoxifen treatment, $\beta$-galactosidase expression could be traced in the $\mathrm{K} 8^{\text {int }}$ cells, in addition to $\mathrm{K}^{\mathrm{hi}}$ cells, in K8-CreER;R26R ${ }^{\mathrm{LaCZ} /+} ; \mathrm{Mirl}^{2} 2 \mathrm{a}^{-/-} ; \mathrm{Pten}^{+/-}$ periportal areas (Figure 6C). For the triple dose of tamoxifen treatment, $\beta$-galactosidase expression was detected in both

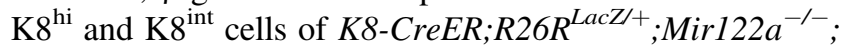
$\mathrm{Pten}^{+/-}$periportal areas (Figure 6D). The $\beta$-galactosidase labeling efficiency in $\mathrm{K} 8^{\text {hi }}$ and $\mathrm{K} 8^{\text {int }}$ cells was quantified and revealed that the $\beta$-galactosidase-labeled $\mathrm{K} 8^{\text {int }}$ cells were significantly increased in the 8 -week tracing $(13.2 \% \pm 6.5 \%$ in a one-dose treatment; $64.2 \% \pm 6.2 \%$ in a triple-dose treatment) compared with that in the 1-week tracing experiment $(0.8 \% \pm 1.8 \%$ in a one-dose treatment; $43.9 \% \pm 6.9 \%$ in a triple-dose treatment) (Figure 6E). Co-IF staining was also performed using antibodies against K19 (oval cell marker) and $\beta$-galactosidase. Under both one- and triple-dose tamoxifen treatment protocols, K19/ $\beta$-galactosidase expression exhibited similar staining patterns (Supplemental Figure S9, A and B) and labeling efficiency (Supplemental Figure S9C) in K8-CreER;R26R ${ }^{\text {LacZ/+ }} ; \mathrm{Mirl}_{2} 2 \mathrm{a}^{-/-} ; \mathrm{Pten}^{+/-}$ periportal areas. In a 30-week trace experiment, liver tumors

\footnotetext{
Figure 2 Inflammation, fibrosis, and putative tumor-initiating lesions in Mir122a ${ }^{-/-} ;$Pten $^{+/-}$premalignant livers. A: Hematoxylin and eosin (H\&E)stained sections reveal periportal areas of Mir122a ${ }^{+/-} ;$Pten $^{+/-}$, Mir122a $a^{-/-}$, and Mir122a ${ }^{-/-} ;$Pten ${ }^{+/-}$livers from 6-month-old mice. Basophilic lesions in Mir122a $^{-/-}$and Mir122a $a^{-1-}$ Pten $^{+/-}$periportal areas are shown at higher magnification in the insets; yellow arrowheads indicate oval cells. Cholangiocytes

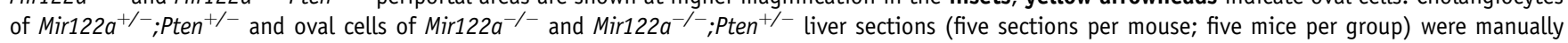
counted and quantified in the bar graph. B: Immunohistochemistry using F4/80 antibody for detecting macrophages, anti-CD3 for detecting T cells, and anti-

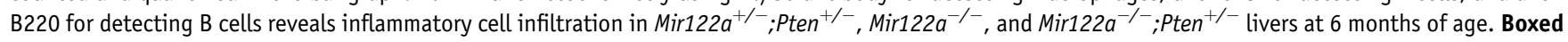
areas depict representative positive staining of F4/80, $C D 3$, and B220 and are shown at higher magnification in the insets. Quantification of F4/80-, CD3-, and B220-expressing cells in the basophilic lesions is shown in the bar graphs. C: Real-time quantitative RT-PCR (RT-qPCR) was used to detect Il1b, Tnf, and Il6 expression in Mir122a $a^{+/} ;$Pten $^{+/-}$, Mir122a $a^{-/-}$, and Mir122a $a^{-/-} ;$Pten $^{+/-}$livers. D: RT-qPCR was used to detect Il1b, Tnf, and Il6 expression in Mir122a ${ }^{+/}$ ${ }^{-} ;$Alb-Cre;Pten ${ }^{f \times /+}$, Mir122a $a^{-/-} ;$Alb-Cre;Pten ${ }^{+/+}$, and Mir122a $a^{-/-} ; A l b$-Cre;Pten ${ }^{f \times /+}$ livers. Relative levels of indicated genes were normalized with Actb

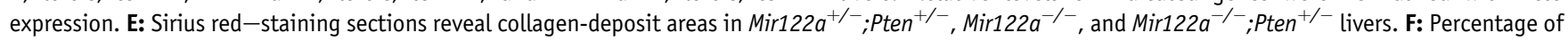
fibrotic areas was quantified by calculating Sirius red-stained collagen-deposited areas and dividing by the yellow-stained hepatic parenchyma. Data are expressed as means \pm SD. $n=5$ mice per group (D and $\mathbf{F})$. ${ }^{*} P<0.05,{ }^{*} P<0.01$, and ${ }^{* *} P<0.005$. Scale bar $=100 \mu \mathrm{m}(\mathbf{A}, \mathbf{B}$, and $\mathbf{E})$. Original magnification, $\times 800$ (A, insets). PV, portal vein.
} 

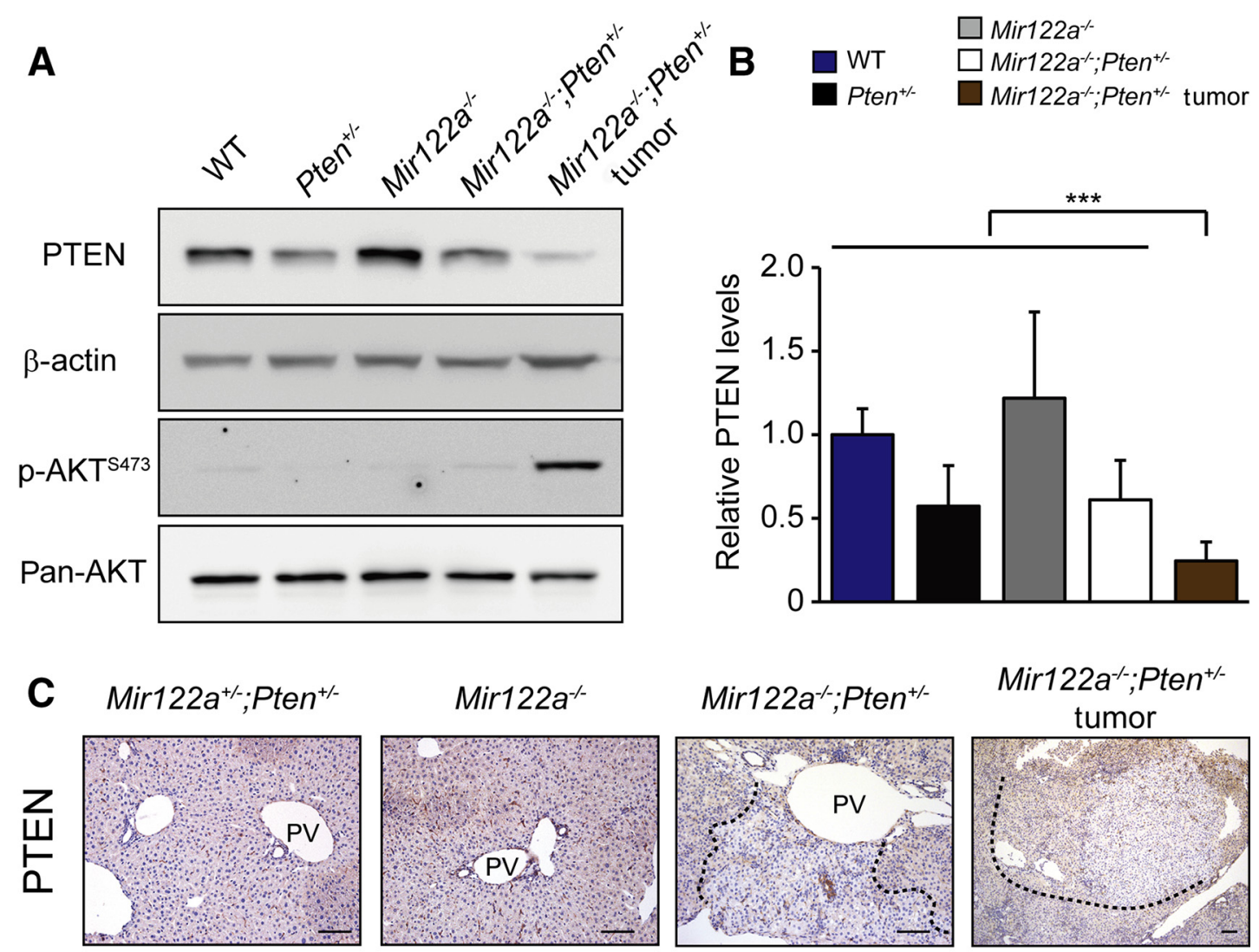

Mir122a $a^{---} ;$Pten $^{+-}$
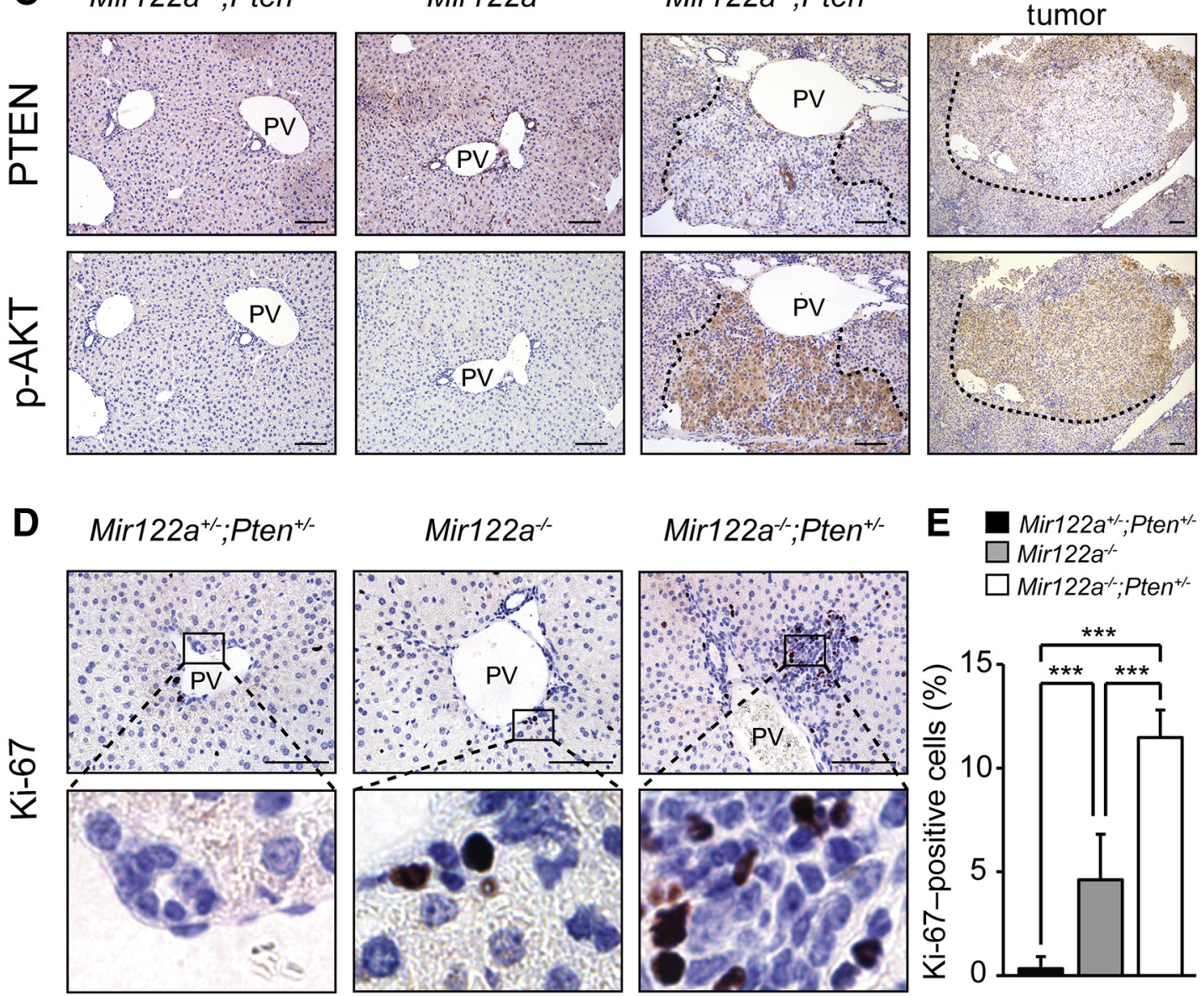

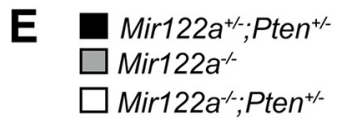

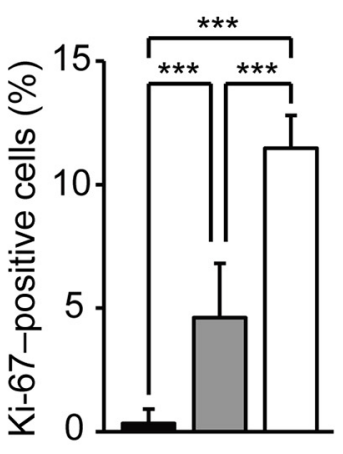

Figure 3 Phosphatase and tensin homolog on chromosome 10 (PTEN) down-regulation, AKT activation, and cellular proliferation detected in periportal

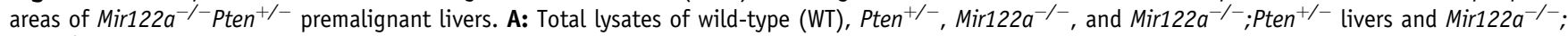
$\mathrm{Pten}^{+/-}$hepatic tumor were used for detecting levels of PTEN and AKT ${ }^{\mathrm{S} 473}$ phosphorylation (p-AKT) by Western blot analysis. $\beta$-Actin and pan-AKT levels were used as internal controls. B: Relative PTEN levels were quantified from multiple experiments of Western blot analysis, as shown in A. C: Immunohistochemical

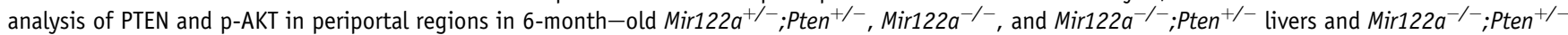

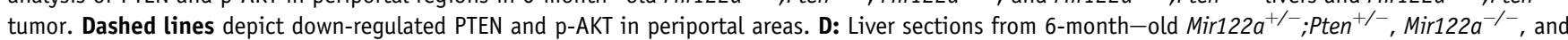
Mir122a $a^{-1-} ;$ Pten $^{+/-}$mice were immunostained with anti-Ki- 67 antibody. Boxed areas in the top panels are shown at higher magnification in the bottom panels. E: Quantification of the percentages of cells stained for Ki-67 by immunohistochemical analysis. Data are expressed as means \pm SD. $n=5$ mice per group (E). ${ }^{* *} P<0.005$. Scale bar $=100 \mu \mathrm{m}$ (C and D). PV, portal vein. 

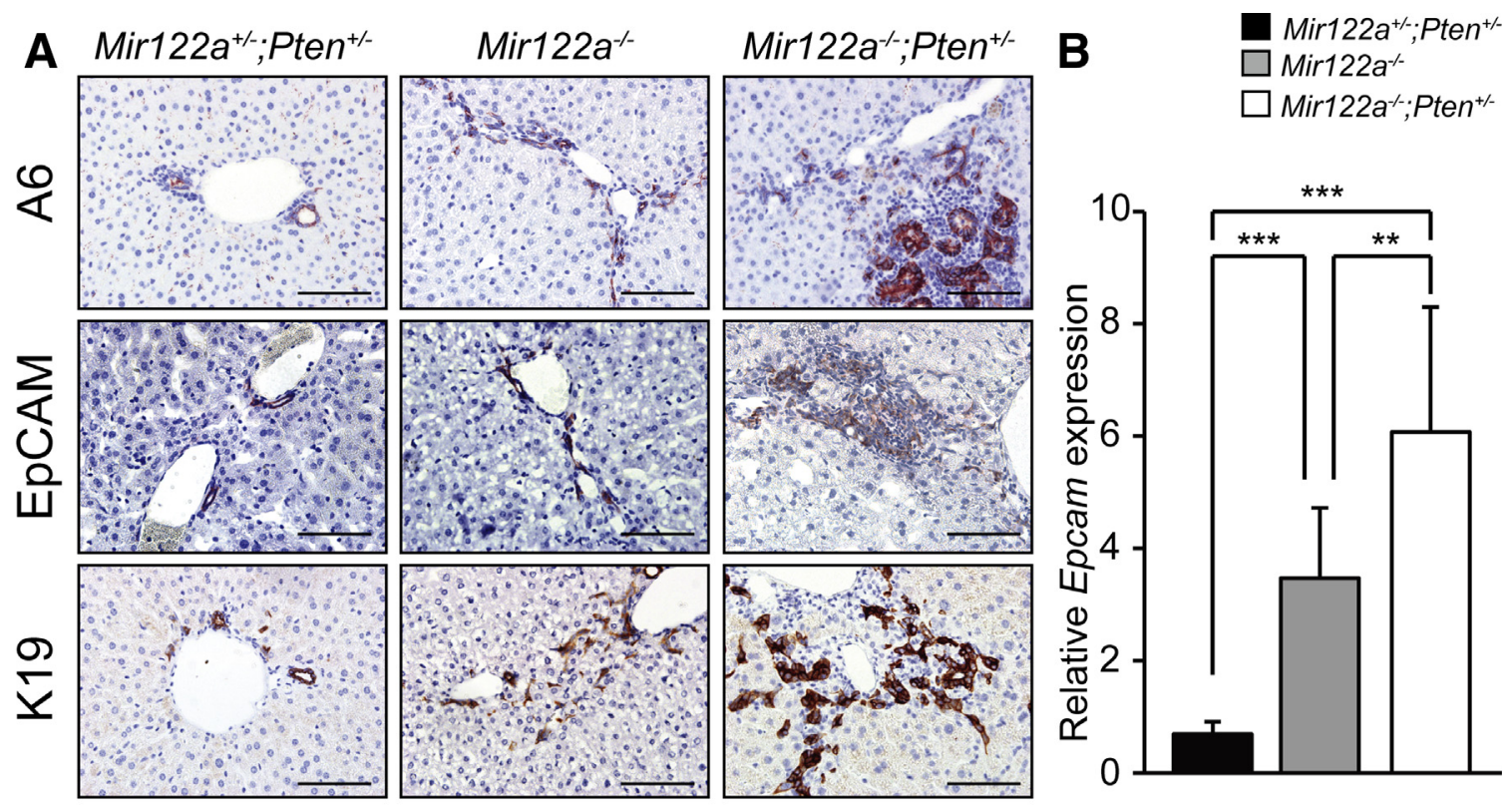

C
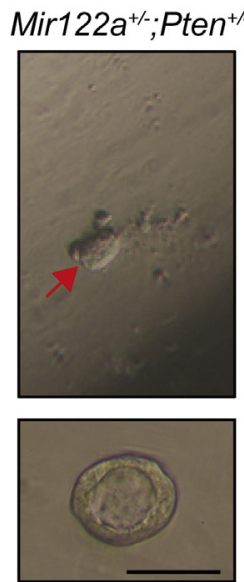
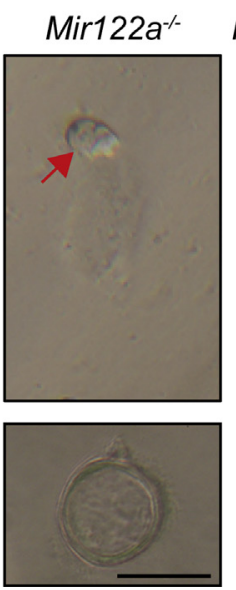

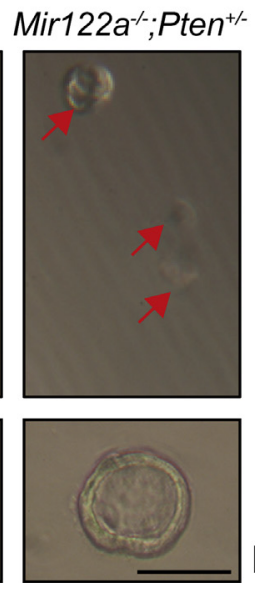

D

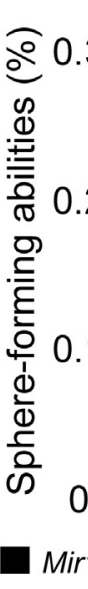

$\mathbf{E}$

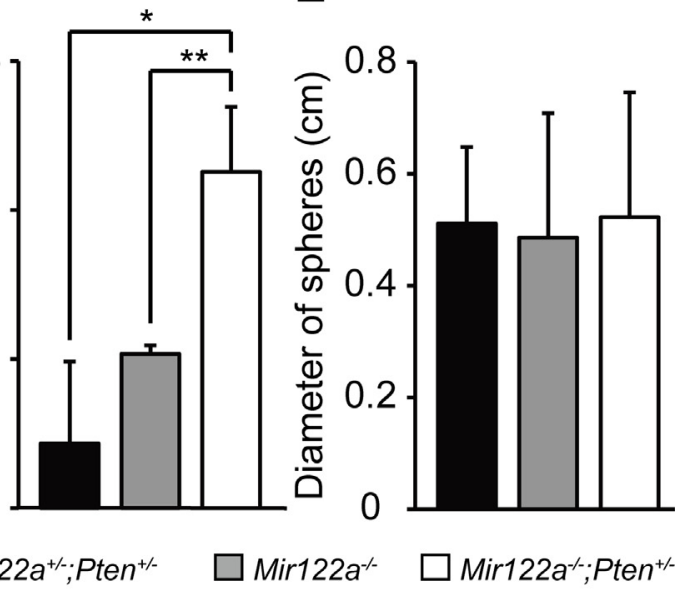

Figure 4 Activation of oval cells occurs in periportal areas in Mir122a $a^{-/} ;$Pten $^{+/-}$premalignant livers. A: Immunohistochemical analysis of oval cell markers

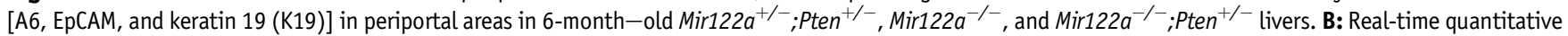
RT-PCR analysis of Epcam expression in 6-month-old Mir122a ${ }^{+/} ;$Pten ${ }^{+/-}$, Mir122a $^{-/-}$, and Mir122a ${ }^{-1-} ;$ Pten $^{+/-}$livers. C: Phase-contrast images of spheres

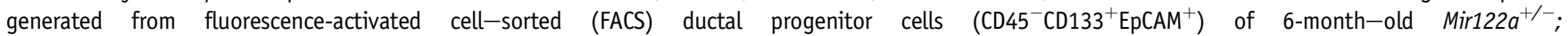
Pten $^{+/-}$, Mir122a $a^{-/-}$, and Mir122a $a_{--} ;$Pten $^{+/-}$livers. Arrows show spheres grown in Matrigel. Top panels show representative images of sphere-forming abilities.

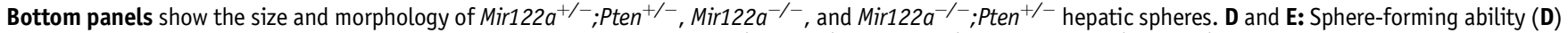

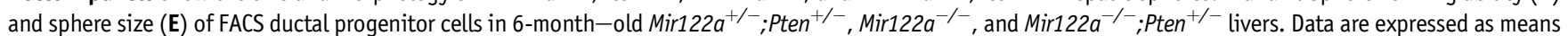
\pm SD. $n=5$ mice per group (B, D, and E). ${ }^{*} P<0.05,{ }^{* *} P<0.01$, and ${ }^{*} * P<0.005$. Scale bars: $100 \mu \mathrm{m}(\mathbf{A}) ; 0.5 \mathrm{~cm}(\mathbf{C})$.

were collected from $\mathrm{K} 8$-CreER;R26R ${ }^{\mathrm{LacZ} /+} ; \mathrm{Mirl}^{2} 2 \mathrm{a}^{-/-}$; $\mathrm{Pten}^{+/-}$mice and whole-mount X-Gal staining was performed. Notably, tamoxifen seemed to suppress tumorigen-

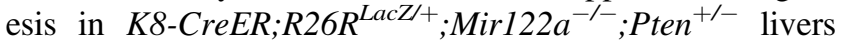
compared with age-matched Mir122a ${ }^{-/} ;$Pten $^{+-}$livers, in which multiple tumors were developed within the same time period. Nonetheless, four tumors were assessed from one-dose and three tumors were assessed from triple-dose tamoxifen-treated K8-CreER;R26R ${ }^{\text {LacZ/+ }}$; Mirl22a $^{-/-} ;$Pten $^{+/-}$mice. X-Gal positively stained tumors (two of three) were found in triple-dose, but none (zero of four) were found in one-dose, tamoxifen administered to $\mathrm{K} 8$-CreER;R26R ${ }^{\mathrm{LacZ} /+} ; \mathrm{Mirl}^{2} 2 \mathrm{a}^{-/-} ; \mathrm{Pten}^{+/-}$ mice (Figure $6 \mathrm{~F}$ ). Under the one-dose tamoxifen treatment, poorly $\beta$-galactosidase-labeled $\mathrm{K} 8^{\text {int }}$ cells after a 1 -week trace (Figure 6E) were correlated with X-Gal negatively stained tumors after a 30 -week trace (Figure 6F). Taken together, the lineage-tracing experiments revealed that the $\mathrm{K} 8^{\text {int }}$ cells were likely generated from $\mathrm{K}^{\text {hi }}{ }_{-}$or K19-expressing oval cells in K8-CreER;R26R ${ }^{L a c Z}$ ${ }^{+} ;$Mirl $22 a^{-/-} ;$Pten $^{+/-}$periportal areas. The expanded $\mathrm{K} 8^{\mathrm{int}}$ hepatocyte-like cells in Mirl22 $a^{-1-} ;$ Pten $^{+/-}$premalignant livers could further act as the cells of origin causing liver tumors. 


\section{A}
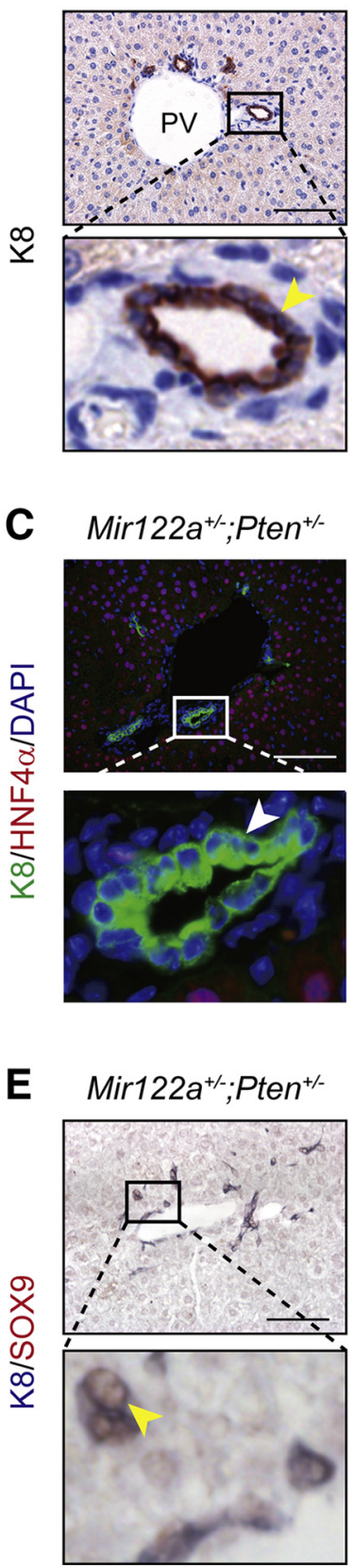

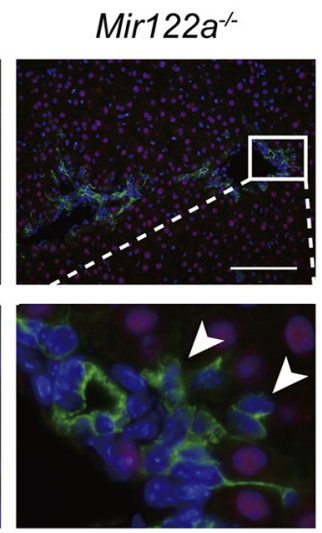

Mir122a-

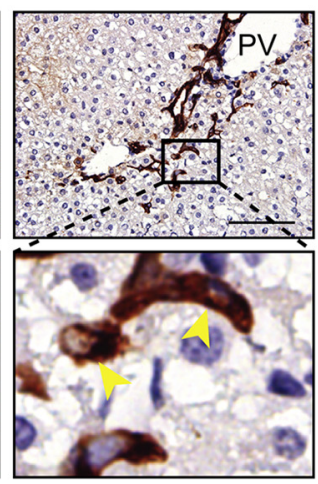

Mir122a-

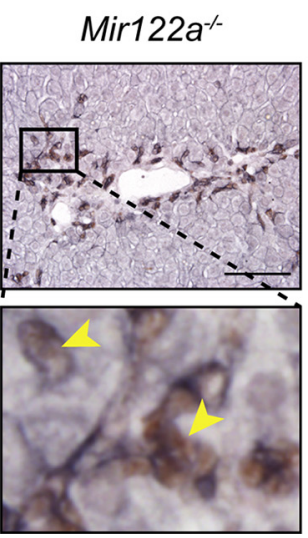

Mir122a $^{-/} ;$Pten $^{+/}$

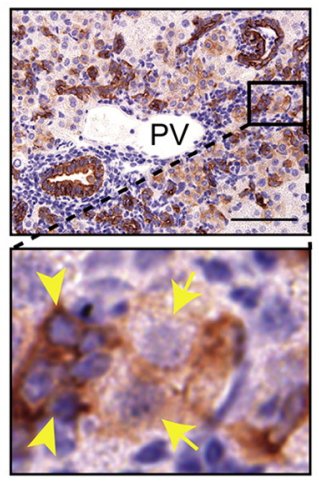

Mir122a $a^{-/} ;$Pten $^{+/}$
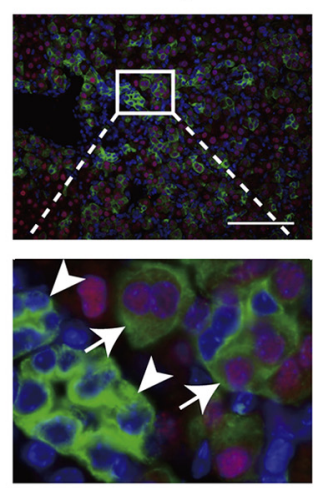

Mir122a ${ }^{-/}, P_{\text {ten }}^{+/}$

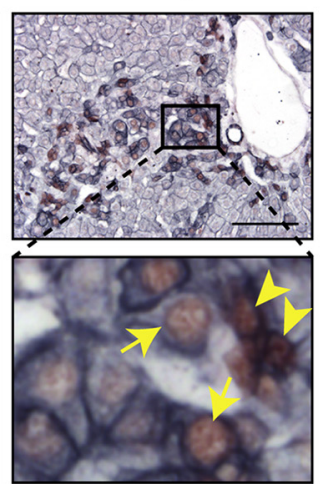

B Mir122a $a^{-/} ;$Pten $^{+/}$

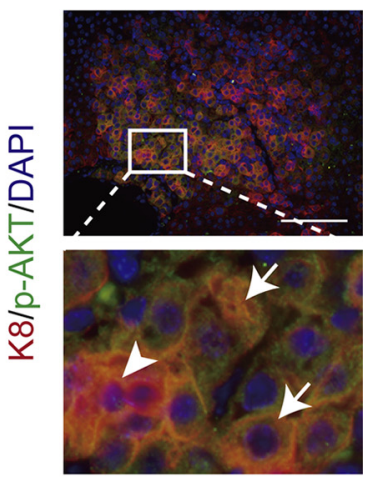

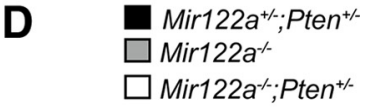

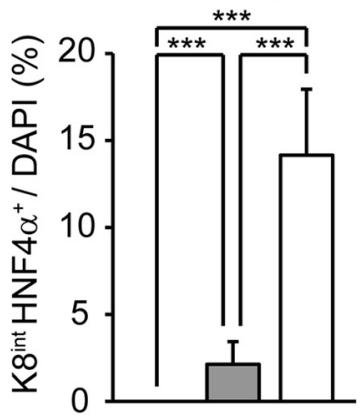

F

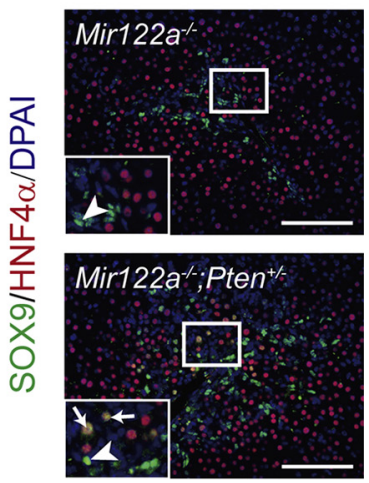

Figure 5 Expanded hepatocyte-like cells express p-AKT, intermediate levels of keratin $8\left(\mathrm{~K}^{\text {int }}\right), \mathrm{HNF} 4 \alpha$, and SOX9 in periportal areas of Mir122a ${ }^{-/-}$Pten ${ }^{+/-}$ premalignant livers. A: Immunohistochemical analysis of $\mathrm{K} 8$ in periportal areas in 6-month-old livers of indicated genotypes. B: Immunofluorescently stained liver sections of 6-month-old Mir122a $a^{-/-}$Pten $^{+/-}$mice reveal the expression of K8 (red) and p-AKT (green). Nuclei were stained by DAPI (blue). C: Immunofluorescence

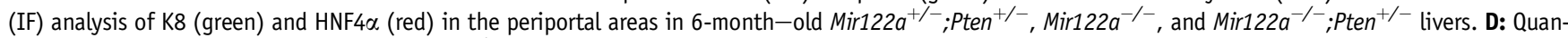
tification of the percentages of cells stained for K8 ${ }^{\text {int }}$ and HNF $4 \alpha$ assessed by IF analysis. E: Dual-colored immunohistochemistry reveals K8 (blue cytoplasm) and SOX9 (red nuclei) expression in the periportal areas in 6-month-old livers of indicated genotypes. A-C and E: Boxed areas in top panels are shown at higher magnification in the bottom panels. Arrowheads and arrows indicate highly intense K8-stained ductular cells and $\mathrm{K} 8^{\text {int }}$ cells, respectively. F: IF-stained liver sections reveal SOX9 (green) and HNF4 $\alpha$ (red) expression in the periportal areas in 6-month-old Mir122a ${ }^{-/-}$and Mir122a ${ }^{-/-}$Pten $^{+/-}$livers. Arrows indicate the cells with double positivity for SOX9 and HNF4 $\alpha$ (yellow). Arrowheads indicate the cells with single positivity for SOX9 (green). Boxed areas are shown at higher magnification in the insets. Data are expressed as means \pm SD. $n=5$ mice per group (D). ${ }^{* * * P}<0.005$. Scale bar $=100 \mu \mathrm{m}(\mathbf{A}-\mathbf{C}, \mathbf{E}$, and F). PV, portal vein.

\section{Discussion}

Our study provides novel genetic evidence to show that Pten is haploinsufficient for Mir122-null HCC initiation and progression in mouse liver. Infiltrating inflammatory cells in the periportal area are associated with locally down-regulated PTEN and up-regulated p-AKT. Also, the ductular cells and $\mathrm{K}^{\text {int }}$ hepatocyte-like cells of 
A

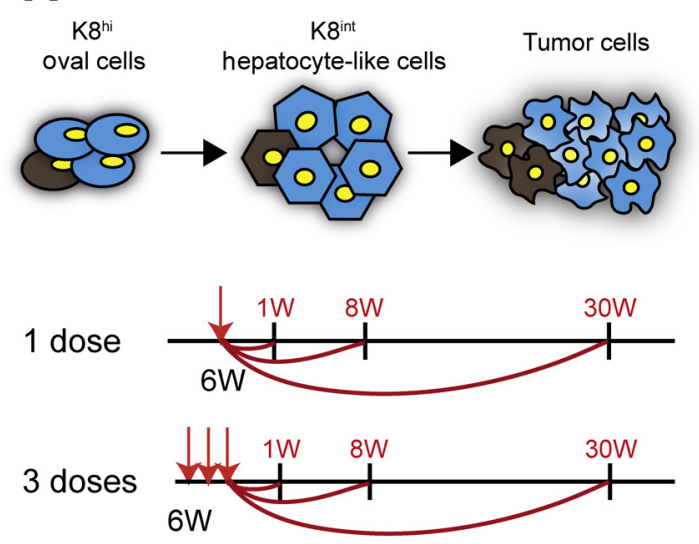

C

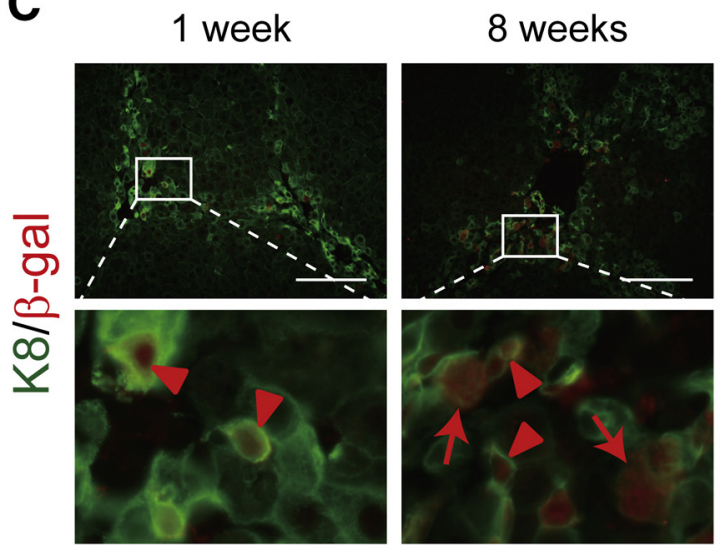

E

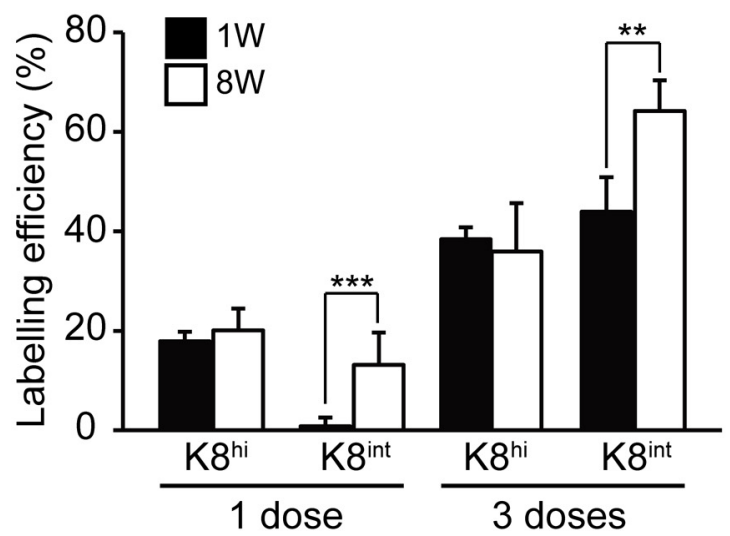

B
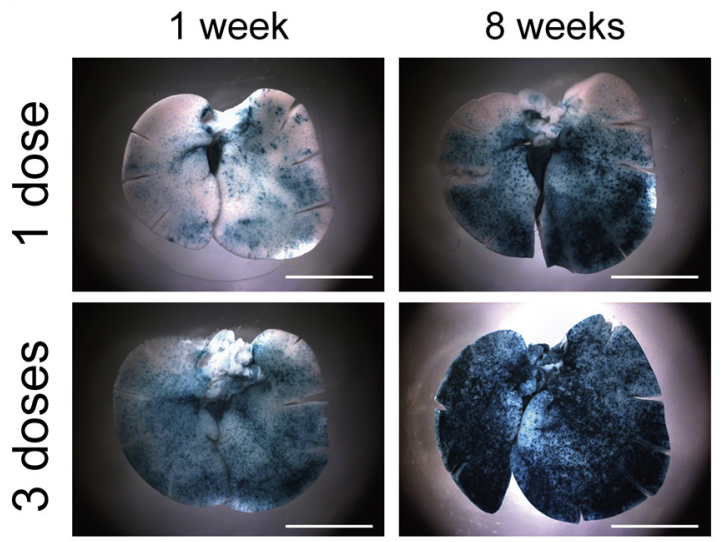

D
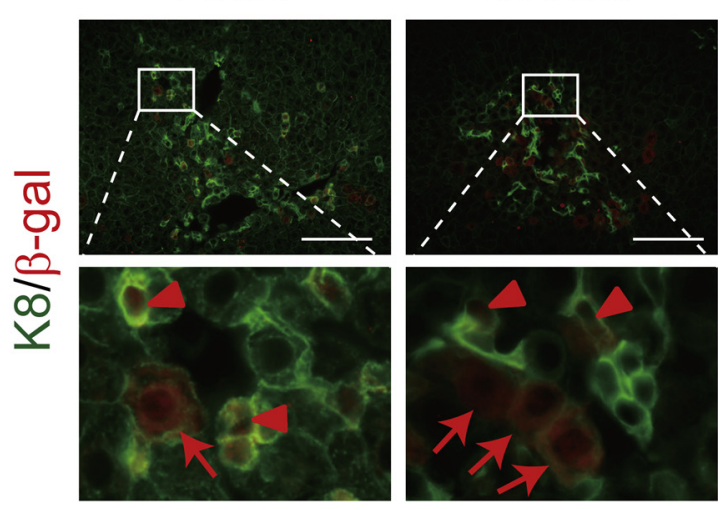

$\mathbf{F}$

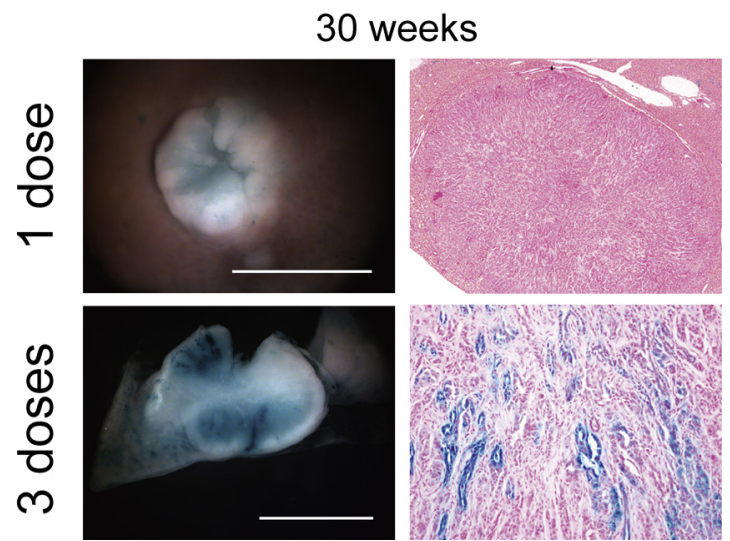

Figure 6 Lineage tracing of highly intense K8-stained ductular cells $\left(\mathrm{K}^{\mathrm{hi}}\right)$ and intermediate levels of $\mathrm{K} 8\left(\mathrm{~K} 8^{\text {int }}\right)$ cells in premalignant livers and hepatic tumors in Mir122a $a^{-1-} ;$ Pten $^{+/-}$mice. A: Hypothetical illustration of $\beta$-Gal-labeled $\mathrm{K} 8^{\text {hi }}$ and $\mathrm{K} 8^{\text {int }}$ cells (blue cells) causing hepatocytic tumor cells in $K 8$ -

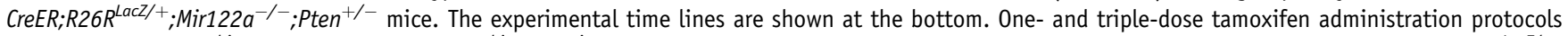
were used to trace $K 8^{\mathrm{hi}}$ cells and to trace both $\mathrm{K} 8^{\mathrm{hi}}$ and $\mathrm{K} 8^{\text {int }}$ cells, respectively. After tamoxifen injection for 1,8 , and 30 weeks $(\mathrm{W})$, the $K 8$-CreER;R26R ${ }^{\text {LacZ/+ }}$; Mir122a $a^{-/-} ;$Pten $^{+/-}$liver samples were harvested for assessing LacZ reporter expression. B: Gross views of X-Gal-stained livers show overall LacZ reporter expression in $K 8-C r e E R ; R 26 R^{\text {LacZ/+}} ;$ Mir122a $a^{-1-} ;$ Pten $^{+/-}$mice at 1 and 8 weeks after one- and triple-dose tamoxifen injections. C and D: Immunofluorescence

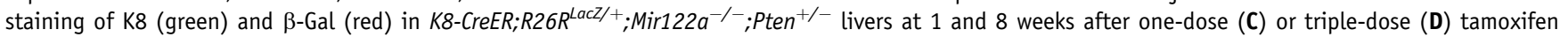
injection. Boxed areas in the top panels are shown at higher magnification in the bottom panels. Arrowheads and arrows indicate K ${ }^{\text {hi }}$ and $K 8^{\text {int }}$ cells,

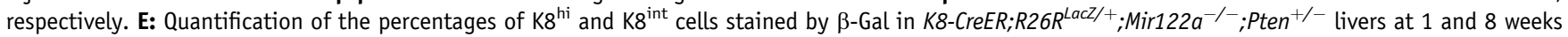
after one- and triple-dose tamoxifen injections. F: Gross (left panels) and histologic (right panels) views of X-Gal-stained K8-CreER;R26R $R^{\text {LacZ/ }+; M i r 122 a^{-\prime}}$ ${ }^{-}$Pten $^{+/-}$liver tumors 30 weeks after one- and triple-dose tamoxifen injection. Nuclei fast red was used for counterstaining in the right panels. Data are expressed as means $\pm \mathrm{SD}(\mathbf{E}) . n=3$ mice per group (E). ${ }^{* *} P<0.01,{ }^{* * *} P<0.005$. Scale bars: $0.5 \mathrm{~cm}(\mathbf{B}) ; 100 \mu \mathrm{m}(\mathbf{C}$ and $\mathbf{D}) ; 0.1 \mathrm{~cm}(\mathbf{F})$. 
Mir122a ${ }^{-/} ;$Pten $^{+/-}$premalignant livers are expanded. Subsequently, down-regulated PTEN and activated AKT promote liver tumor initiation and progression in the Mir122a-null background. Lineage-tracing experiments under different tamoxifen-induced $\mathrm{LacZ}$ reporter tracing among K8-expressing cells in Mirl22a ${ }^{-/-} \mathrm{Pten}^{+/-}$premalignant livers enabled us to demonstrate that $K 8^{\text {int }}$ hepatocyte-like cells are derived from $\mathrm{K} 8{ }^{\text {hi }}$ cells and can be the cells of origin for liver tumor initiation and progression. However, the lower $\beta$-galactosidase-labeling efficiency in $\mathrm{K} 8{ }^{\text {int }}$ hepatocyte-like cells (approximately $1 \%$ in 1 -week trace; approximately $13 \%$ in 8 -week trace) after a onedose tamoxifen induction appears to be inefficient for long-term (30-week) lineage tracing, which limits our finding to identify $\mathrm{X}-\mathrm{Gal}$-positive tumors.

Interestingly, the $\mathrm{K} 8^{\text {int }}$ cells identified in the periportal area in this study express SOX9 and hepatocyte marker HNF4 $\alpha$ that resemble the hybrid hepatocytes in a previous report. ${ }^{39}$ However, the hybrid hepatocyte cells, previously described by Font-Burgada et al, ${ }^{39}$ cannot cause a chemicalor diet-induced liver tumor. In this study, down-regulation of PTEN or activation of AKT appears to be the crucial step for generating $\mathrm{K} 8^{\text {int }}$ hepatocyte-like cells. Immunohistologic analysis and lineage-tracing experiments revealed that the $\mathrm{K} 8^{\text {int }}$ hepatocyte-like cells are often juxtaposed with the $\mathrm{K} 8^{\text {hi }}$ oval cells and are derived from $\mathrm{K} 8^{\text {hi }}$ oval cells in Mir122a ${ }^{-/-}$Pten $^{+/-}$premalignant livers. Thus, these findings suggest that PTEN down-regulation in Mir122a-null oval cells and their derivatives in periportal areas can drive HCC initiation and progression. Although the previous reports demonstrate that the oval cells generated from various mouse liver disease models fail to cause $\mathrm{HCC},{ }^{38-40}$ our results suggest that periportal inflammatory and fibrotic microenvironments can induce certain oncogenic insults (ie, PTEN down-regulation or AKT activation) that promote periportal oval-to-hepatocyte-like cell expansion and tumorigenesis.

DEN is a potent carcinogen driving hepatic tumorigenesis in rodents. Bioactive DEN requires cytochrome p450 enzymes, including Cyp2E1, in the differentiated hepatocytes located at the pericentrilobular area. ${ }^{54,55}$ On DEN administration, the Mir122a-null mice are susceptible to biliary cystogenesis and hepatocellular carcinogenesis, suggesting that Mir122a has a protective role against the hepatotoxic consequences of DEN. ${ }^{56}$ In this study, hepatocellular tumors, but not biliary cyst formation, were observed in Mirl22a $a^{-1-}$ Pten $^{+/-}$mice. This finding suggests that PTEN down-regulation and AKT activation in Mirl22-null livers are crucial for driving hepatocellular tumorigenesis, but not required for biliary cystogenesis.

In the current study, PTEN down-regulation specifically occurred in periportal parenchyma and was associated with infiltrating inflammatory cells. The inflammatory phenomena and local PTEN down-regulation appeared to be independent of the sex; thereby, no significant sex-related differences were observed in liver tumor development in both Mirl22a $a^{-/-}$Pten $^{+/-}$and Mirl22a $a^{-/-} ; A l b-C r e ;$ Pten $^{f x /+}$ mice. According to the previous reports, ${ }^{51-53}$ IL-1 $\beta /$ TNF$\alpha$-mediated NF- $\kappa \mathrm{B}$ signaling might be one of the potential antagonistic mechanisms to down-regulate PTEN levels. However, other mechanisms causing PTEN downregulation in hepatic periportal microenvironments cannot be ruled out. A recent study shows that microenvironmentinduced PTEN down-regulation by exosomal miRNAs promotes brain metastasis outgrowth. ${ }^{57}$ In the Mir122a-null liver, aberrantly produced exosomal miRNAs that target Pten mRNA in periportal parenchyma remain unclear and require further investigation.

In summary, this study shows that PTEN levels are crucial to control the initiation and expansion of hepatocytelike tumor cells under periportal inflammatory and fibrotic microenvironments in Mir122a-null background. By generating compound mutants in mice, this approach facilitates our understanding in the cooperatively suppressive mechanism of Mir122a and Pten in mouse hepatocellular carcinogenesis that may explain the consequences of downregulation of both tumor suppressors in patients with HCC.

\section{Acknowledgments}

We thank Drs. Hsin-Fang Yang-Yen and Jeou-Yuan Chen for comments on this study; the Taiwan Mouse Clinic, National Phenotyping and Drug Testing Center (Academia Sinica, Taipei, Taiwan) for technical support; and the Developmental Studies Hybridoma Bank, which was started by the Eunice Kennedy Shriver National Institute of Child Health and Human Development of the $\mathrm{NIH}$, at the University of Iowa for maintaining the A6 (A6 BCM, distributed by Valentina M. Factor), EpCAM (G8.8, distributed by Andrew G. Farr), keratin 8 (TROMA-I, distributed by Philippe Brulet and Rolf Kemler), and keratin 19 (TROMAIII, distributed by Rolf Kemler) monoclonal antibodies.

W.-L.T. and C.-M.C. designed the experiments, analyzed the data, and wrote the article; W.-L.T. performed the experiments; and W.-L.T., L.-R.Y., A.-P.T., and C.-M.C. interpreted data and provided critical input.

\section{Supplemental Data}

Supplemental material for this article can be found at https://doi.org/10.1016/j.ajpath.2018.07.019.

\section{References}

1. Bosch FX, Ribes J, Díaz M, Cléries R: Primary liver cancer: worldwide incidence and trends. Gastroenterology 2004, 127: S5-S16

2. El-Serag HB, Rudolph KL: Hepatocellular carcinoma: epidemiology and molecular carcinogenesis. Gastroenterology 2007, 132:2557-2576

3. Altekruse SF, McGlynn KA, Reichman ME: Hepatocellular carcinoma incidence, mortality, and survival trends in the United States from 1975 to 2005. J Clin Oncol 2009, 27:1485-1491 
4. Patel T: Increasing incidence and mortality of primary intrahepatic cholangiocarcinoma in the United States. Hepatology 2001, 33: $1353-1357$

5. Lagos-Quintana M, Rauhut R, Yalcin A, Meyer J, Lendeckel W, Tuschl T: Identification of tissue-specific microRNAs from mouse. Curr Biol 2002, 12:735-739

6. Chang J, Nicolas E, Marks D, Sander C, Lerro A, Buendia MA, Xu C, Mason WS, Moloshok T, Bort R, Zaret KS, Taylor JM: miR122, a mammalian liver-specific microRNA, is processed from her mRNA and may downregulate the high affinity cationic amino acid transporter CAT-1. RNA Biol 2004, 1:106-113

7. Xu H, He JH, Xiao ZD, Zhang QQ, Chen YQ, Zhou H, Qu LH: Liver-enriched transcription factors regulate microRNA-122 that targets CUTL1 during liver development. Hepatology 2010, 52: $1431-1442$

8. Krutzfeldt J, Rajewsky N, Braich R, Rajeev KG, Tuschl T, Manoharan M, Stoffel M: Silencing of microRNAs in vivo with "antagomirs". Nature 2005, 438:685-689

9. Esau C, Davis S, Murray SF, Yu XX, Pandey SK, Pear M, Watts L, Booten SL, Graham M, McKay R, Subramaniam A, Propp S, Lollo BA, Freier S, Bennett CF, Bhanot S, Monia BP: miR-122 regulation of lipid metabolism revealed by in vivo antisense targeting. Cell Metab 2006, 3:87-98

10. Kutay H, Bai S, Datta J, Motiwala T, Pogribny I, Frankel W, Jacob ST, Ghoshal K: Downregulation of miR-122 in the rodent and human hepatocellular carcinomas. J Cell Biochem 2006, 99: 671-678

11. Gramantieri L, Ferracin M, Fornari F, Veronese A, Sabbioni S, Liu CG, Calin GA, Giovannini C, Ferrazzi E, Grazi GL, Croce CM, Bolondi L, Negrini M: Cyclin G1 is a target of miR-122a, a microRNA frequently down-regulated in human hepatocellular carcinoma. Cancer Res 2007, 67:6092-6099

12. Tsai WC, Hsu PW, Lai TC, Chau GY, Lin CW, Chen CM, Lin CD, Liao YL, Wang JL, Chau YP, Hsu MT, Hsiao M, Huang HD, Tsou AP: MicroRNA-122, a tumor suppressor microRNA that regulates intrahepatic metastasis of hepatocellular carcinoma. Hepatology 2009, 49:1571-1582

13. Bai S, Nasser MW, Wang B, Hsu SH, Datta J, Kutay H, Yadav A, Nuovo G, Kumar P, Ghoshal K: MicroRNA-122 inhibits tumorigenic properties of hepatocellular carcinoma cells and sensitizes these cells to sorafenib. J Biol Chem 2009, 284:32015-32027

14. Coulouarn C, Factor VM, Andersen JB, Durkin ME, Thorgeirsson SS: Loss of miR-122 expression in liver cancer correlates with suppression of the hepatic phenotype and gain of metastatic properties. Oncogene 2009, 28:3526-3536

15. Fornari F, Gramantieri L, Giovannini C, Veronese A, Ferracin M, Sabbioni S, Calin GA, Grazi GL, Croce CM, Tavolari S, Chieco P, Negrini M, Bolondi L: MiR-122/cyclin G1 interaction modulates p53 activity and affects doxorubicin sensitivity of human hepatocarcinoma cells. Cancer Res 2009, 69:5761-5767

16. Tsai WC, Hsu SD, Hsu CS, Lai TC, Chen SJ, Shen R, Huang Y, Chen HC, Lee CH, Tsai TF, Hsu MT, Wu JC, Huang HD, Shiao MS, Hsiao M, Tsou AP: MicroRNA-122 plays a critical role in liver homeostasis and hepatocarcinogenesis. J Clin Invest 2012, 122: 2884-2897

17. Hsu SH, Wang B, Kota J, Yu J, Costinean S, Kutay H, Yu L, Bai S, La Perle K, Chivukula RR, Mao H, Wei M, Clark KR, Mendell JR, Caligiuri MA, Jacob ST, Mendell JT, Ghoshal K: Essential metabolic, anti-inflammatory, and anti-tumorigenic functions of miR-122 in liver. J Clin Invest 2012, 122:2871-2883

18. Li DM, Sun H: TEP1, encoded by a candidate tumor suppressor locus, is a novel protein tyrosine phosphatase regulated by transforming growth factor beta. Cancer Res 1997, 57:2124-2129

19. Steck PA, Pershouse MA, Jasser SA, Yung WK, Lin H, Ligon AH, Langford LA, Baumgard ML, Hattier T, Davis T, Frye C, Hu R, Swedlund B, Teng DH, Tavtigian SV: Identification of a candidate tumour suppressor gene, MMAC1, at chromosome
$10 \mathrm{q} 23.3$ that is mutated in multiple advanced cancers. Nat Genet 1997, 15:356-362

20. Li J, Yen C, Liaw D, Podsypanina K, Bose S, Wang SI, Puc J, Miliaresis C, Rodgers L, McCombie R, Bigner SH, Giovanella BC, Ittmann M, Tycko B, Hibshoosh H, Wigler MH, Parsons R: PTEN, a putative protein tyrosine phosphatase gene mutated in human brain, breast, and prostate cancer. Science 1997, 275:1943-1947

21. Ali IU, Schriml LM, Dean M: Mutational spectra of PTEN/MMAC1 gene: a tumor suppressor with lipid phosphatase activity. J Natl Cancer Inst 1999, 91:1922-1932

22. Sze KM, Wong KL, Chu GK, Lee JM, Yau TO, Oi-Lin Ng I: Loss of phosphatase and tensin homolog enhances cell invasion and migration through AKT/Sp-1 transcription factor/matrix metalloproteinase 2 activation in hepatocellular carcinoma and has clinicopathologic significance. Hepatology 2011, 53:1558-1569

23. Zhou L, Huang Y, Li J, Wang Z: The mTOR pathway is associated with the poor prognosis of human hepatocellular carcinoma. Med Oncol 2010, 27:255-261

24. Chen JS, Wang Q, Fu XH, Huang XH, Chen XL, Cao LQ, Chen LZ, Tan HX, Li W, Bi J, Zhang LJ: Involvement of PI3K/PTEN/AKT/mTOR pathway in invasion and metastasis in hepatocellular carcinoma: association with MMP-9. Hepatol Res 2009, 39:177-186

25. Mo L, Zheng X, Huang HY, Shapiro E, Lepor H, Cordon-Cardo C, Sun TT, Wu XR: Hyperactivation of Ha-ras oncogene, but not Ink4a/Arf deficiency, triggers bladder tumorigenesis. J Clin Invest 2007, 117:314-325

26. Hu TH, Huang CC, Lin PR, Chang HW, Ger LP, Lin YW, Changchien CS, Lee CM, Tai MH: Expression and prognostic role of tumor suppressor gene PTEN/MMAC1/TEP1 in hepatocellular carcinoma. Cancer 2003, 97:1929-1940

27. Villanueva A, Chiang DY, Newell P, Peix J, Thung S, Alsinet C, Tovar V, Roayaie S, Minguez B, Sole M, Battiston C, Van Laarhoven S, Fiel MI, Di Feo A, Hoshida Y, Yea S, Toffanin S, Ramos A, Martignetti JA, Mazzaferro V, Bruix J, Waxman S, Schwartz M, Meyerson M, Friedman SL, Llovet JM: Pivotal role of mTOR signaling in hepatocellular carcinoma. Gastroenterology 2008, 135:1972-1983. 1983.e1-11

28. Yeh KT, Chang JG, Chen YJ, Chen ST, Yu SY, Shih MC, Perng LI, Wang JC, Tsai M, Chang CP: Mutation analysis of the putative tumor suppressor gene PTEN/MMAC1 in hepatocellular carcinoma. Cancer Invest 2000, 18:123-129

29. Fujiwara Y, Hoon DS, Yamada T, Umeshita K, Gotoh M, Sakon M, Nishisho I, Monden M: PTEN/MMAC1 mutation and frequent loss of heterozygosity identified in chromosome $10 \mathrm{q}$ in a subset of hepatocellular carcinomas. Jpn J Cancer Res 2000, 91:287-292

30. Yao YJ, Ping XL, Zhang $\mathrm{H}$, Chen FF, Lee PK, Ahsan H, Chen CJ, Lee PH, Peacocke M, Santella RM, Tsou HC: PTEN/MMAC1 mutations in hepatocellular carcinomas. Oncogene 1999, 18:3181-3185

31. Horie Y, Suzuki A, Kataoka E, Sasaki T, Hamada K, Sasaki J, Mizuno K, Hasegawa G, Kishimoto H, lizuka M, Naito M, Enomoto K, Watanabe S, Mak TW, Nakano T: Hepatocyte-specific Pten deficiency results in steatohepatitis and hepatocellular carcinomas. J Clin Invest 2004, 113:1774-1783

32. Stiles B, Wang Y, Stahl A, Bassilian S, Lee WP, Kim YJ, Sherwin R, Devaskar S, Lesche R, Magnuson MA, Wu H: Liver-specific deletion of negative regulator Pten results in fatty liver and insulin hypersensitivity [corrected]. Proc Natl Acad Sci U S A 2004, 101:2082-2087

33. Rountree CB, Ding W, He L, Stiles B: Expansion of CD133expressing liver cancer stem cells in liver-specific phosphatase and tensin homolog deleted on chromosome 10-deleted mice. Stem Cells 2009, 27:290-299

34. Sell S, Leffert HL: Liver cancer stem cells. J Clin Oncol 2008, 26: 2800-2805

35. Golding M, Sarraf C, Lalani EN, Alison MR: Reactive biliary epithelium: the product of a pluripotential stem cell compartment? Hum Pathol 1996, 27:872-884 
36. Gouw AS, Clouston AD, Theise ND: Ductular reactions in human liver: diversity at the interface. Hepatology 2011, 54:1853-1863

37. Roskams T: Liver stem cells and their implication in hepatocellular and cholangiocarcinoma. Oncogene 2006, 25:3818-3822

38. Jors S, Jeliazkova P, Ringelhan M, Thalhammer J, Durl S, Ferrer J, Sander M, Heikenwalder M, Schmid RM, Siveke JT, Geisler F: Lineage fate of ductular reactions in liver injury and carcinogenesis. J Clin Invest 2015, 125:2445-2457

39. Font-Burgada J, Shalapour S, Ramaswamy S, Hsueh B, Rossell D, Umemura A, Taniguchi K, Nakagawa H, Valasek MA, Ye L, Kopp JL, Sander M, Carter H, Deisseroth K, Verma IM, Karin M: Hybrid periportal hepatocytes regenerate the injured liver without giving rise to cancer. Cell 2015, 162:766-779

40. Mu X, Espanol-Suner R, Mederacke I, Affo S, Manco R, Sempoux C, Lemaigre FP, Adili A, Yuan D, Weber A, Unger K, Heikenwalder M, Leclercq IA, Schwabe RF: Hepatocellular carcinoma originates from hepatocytes and not from the progenitor/biliary compartment. J Clin Invest 2015, 125:3891-3903

41. Tummala Krishna S, Gomes Ana L, Yilmaz M, Graña O, Bakiri L, Ruppen I, Ximénez-Embún P, Sheshappanavar V, RodriguezJusto M, Pisano David G, Wagner Erwin F, Djouder N: Inhibition of de novo NAD + synthesis by oncogenic URI causes liver tumorigenesis through DNA damage. Cancer Cell 2014, 26:826-839

42. Tummala KS, Brandt M, Teijeiro A, Grana O, Schwabe RF, Perna C, Djouder N: Hepatocellular carcinomas originate predominantly from hepatocytes and benign lesions from hepatic progenitor cells. Cell Rep 2017, 19:584-600

43. Lesche R, Groszer M, Gao J, Wang Y, Messing A, Sun H, Liu X, $\mathrm{Wu} \mathrm{H}$ : Cre/loxP-mediated inactivation of the murine Pten tumor suppressor gene. Genesis 2002, 32:148-149

44. O'Gorman S, Dagenais NA, Qian M, Marchuk Y: Protamine-Cre recombinase transgenes efficiently recombine target sequences in the male germ line of mice, but not in embryonic stem cells. Proc Natl Acad Sci U S A 1997, 94:14602-14607

45. Postic C, Shiota M, Niswender KD, Jetton TL, Chen Y, Moates JM, Shelton KD, Lindner J, Cherrington AD, Magnuson MA: Dual roles for glucokinase in glucose homeostasis as determined by liver and pancreatic $\beta$ cell-specific gene knock-outs using Cre recombinase. J Biol Chem 1999, 274:305-315

46. Chen C-M, Lu T-L, Su F-Y, You L-R: Susceptibility of epithelium to PTEN-deficient tumorigenesis. Tumor Suppressor Genes. Edited by Cheng P. London, UK: InTech, 2012. pp. 35-52
47. Lu T-L, Huang Y-F, You L-R, Chao N-C, Su F-Y, Chang J-L, Chen C-M: Conditionally ablated Pten in prostate basal cells promotes basal-to-luminal differentiation and causes invasive prostate cancer in mice. Am J Pathol 2013, 182:975-991

48. Mao X, Fujiwara Y, Orkin SH: Improved reporter strain for monitoring Cre recombinase-mediated DNA excisions in mice. Proc Natl Acad Sci U S A 1999, 96:5037-5042

49. Lu T-L, Chang J-L, Liang C-C, You L-R, Chen C-M: Tumor spectrum, tumor latency and tumor incidence of the Pten-deficient mice. PLoS One 2007, 2:e1237

50. Liang C-C, You LR, Chang J-L, Tsai T-F, Chen C-M: Transgenic mice exhibiting inducible and spontaneous Cre activities driven by a bovine keratin 5 promoter that can be used for the conditional analysis of basal epithelial cells in multiple organs. J Biomed Sci 2009, 16:2

51. Kim S, Domon-Dell C, Kang J, Chung DH, Freund JN, Evers BM: Down-regulation of the tumor suppressor PTEN by the tumor necrosis factor-alpha/nuclear factor-kappaB (NF-kappaB)-inducing kinase/NF-kappaB pathway is linked to a default IkappaB-alpha autoregulatory loop. J Biol Chem 2004, 279:4285-4291

52. Vasudevan KM, Gurumurthy S, Rangnekar VM: Suppression of PTEN expression by NF-kappa B prevents apoptosis. Mol Cell Biol 2004, 24:1007-1021

53. Hai Ping P, Feng Bo T, Li L, Nan Hui Y, Hong Z: IL-1beta/NF-kb signaling promotes colorectal cancer cell growth through miR181a/PTEN axis. Arch Biochem Biophys 2016, 604:20-26

54. Bühler R, Lindros KO, Nordling $\AA$, Johansson I, IngelmanSundberg M: Zonation of cytochrome P450 isozyme expression and induction in rat liver. Eur J Biochem 1992, 204:407-412

55. Kang JS, Wanibuchi H, Morimura K, Gonzalez FJ, Fukushima S: Role of CYP2E1 in diethylnitrosamine-induced hepatocarcinogenesis in vivo. Cancer Res 2007, 67:11141-11146

56. Hsu SH, Wang B, Kutay H, Bid H, Shreve J, Zhang X, Costinean S, Bratasz A, Houghton P, Ghoshal K: Hepatic loss of miR-122 predisposes mice to hepatobiliary cyst and hepatocellular carcinoma upon diethylnitrosamine exposure. Am J Pathol 2013, 183: $1719-1730$

57. Zhang L, Zhang S, Yao J, Lowery FJ, Zhang Q, Huang WC, Li P, Li M, Wang X, Zhang C, Wang H, Ellis K, Cheerathodi M, McCarty JH, Palmieri D, Saunus J, Lakhani S, Huang S, Sahin AA, Aldape KD, Steeg PS, Yu D: Microenvironment-induced PTEN loss by exosomal microRNA primes brain metastasis outgrowth. Nature 2015, 527:100-104 